\title{
Incidence of gastroduodenal ulcers in patients with rheumatoid arthritis after 12 weeks of rofecoxib, naproxen, or placebo: a multicentre, randomised, double blind study
}

\author{
C J Hawkey, L Laine, T Simon, H Quan, S Shingo, J Evans, on behalf of the Rofecoxib \\ Rheumatoid Arthritis Endoscopy Study Group
}

\begin{abstract}
Background: Previous studies in patients with osteoarthritis have suggested that the selective cyclooxygenase (COX)-2 inhibitor rofecoxib results in less gastrointestinal damage than non-selective non-steroidal antiinflammatory drugs (NSAIDs). This study compared the incidence of endoscopically detected gastroduodenal ulcers in rheumatoid arthritis patients treated with rofecoxib or a non-selective NSAID.

Methods: In this multicentre, randomised, double blind, 12 week study, patients with rheumatoid arthritis were allocated to rofecoxib $50 \mathrm{mg}$ once daily ( $\mathrm{n}=219)$, naproxen $500 \mathrm{mg}$ twice daily $(n=220)$, or placebo $(n=221)$. Endoscopy was performed at baseline and at six and 12 weeks. Lifetable analysis and log rank tests were used to analyse the incidence of gastroduodenal ulcers $\geqslant 3 \mathrm{~mm}$. Gastric or duodenal ulcers $\geqslant 5 \mathrm{~mm}$ and erosions were also evaluated as secondary end points. Tolerability was assessed by adverse events. Results: The cumulative incidence of ulcers $\geqslant 3 \mathrm{~mm}$ at 12 weeks was significantly higher in patients on naproxen $(25.5 \%)$ than in patients receiving rofecoxib $16.8 \%$; difference $18.7 \% 195 \%$ confidence interval (Cl) $11.7 \%, 25.7 \%)$; $p<0.001)$ or placebo $(2.9 \%$; difference $22.6 \%(95 \% \mathrm{Cl} 16.1 \%, 29.1 \%)$; $\mathrm{p}<0.001)$. The difference between rofecoxib (6.8\%) and placebo (2.9\%) did not reach statistical significance $(p=0.066)$. Results were similar for ulcers $\geqslant 5 \mathrm{~mm}$ and for mean changes from baseline in the number of gastroduodenal erosions. The overall incidence of clinical adverse events was similar among treatment groups $161 \%$ of patients on placebo, $62 \%$ in patients on rofecoxib, and $66 \%$ in patients on naproxen).

Conclusions: Rofecoxib $50 \mathrm{mg}$ daily (twice the dose recommended for this patient population) resulted in a lower incidence of endoscopically detected gastroduodenal ulcers and erosions than treatment with naproxen 500 mg twice daily.
\end{abstract}

See end of article for authors' affiliations

Correspondence to: Professor C J Hawkey, School of Medical and Surgical Sciences, Division of Gastroenterology, University Hospital, Nottingham NG7 2UH, UK:

cj.hawkey@nottingham.ac.uk

Accepted for publication 17 December 2002

$\mathrm{T}$ he potential of non-steroidal antiinflammatory drugs (NSAIDs) to cause gastrointestinal toxicity is well known, with an estimated 100000 hospitalisations occurring annually in the USA due to NSAID related serious gastrointestinal complications. ${ }^{1}$ Chronic use of NSAIDs puts patients at risk for perforations, ulcers, or haemorrhage of the gastroduodenal mucosa. ${ }^{2}$ It has been postulated that these deleterious effects are a result of inhibition of cyclooxygenase (COX)-1, the isoform of the enzyme cyclooxygenase believed to catalyse the synthesis of gastroprotective prostaglandins. By contrast, NSAIDs are thought to achieve their antiinflammatory or analgesic efficacy by inhibition of COX-2, the isoform involved in inflammatory responses. ${ }^{3}$ The lack of selectivity of traditional NSAIDs for a particular COX isoform is a likely explanation for the apparent inseparability of the toxic effect of COX-1 inhibition and the therapeutic effect of COX-2 inhibition seen with these agents. This has led to the development of COX-2 selective inhibitors, based on the premise that preferential inhibition of the isoform relevant to inflammation (COX-2) would be expected to convey the same therapeutic benefit of traditional NSAIDs with significantly less gastrointestinal toxicity due to inhibition of COX-1. ${ }^{3}$

Current knowledge of the COX-2 inhibitor rofecoxib has been consistent with the COX-2 hypothesis, in that rofecoxib is not only as effective as non-selective NSAIDs but is also well tolerated both in general and in terms of the gastrointestinal system. $^{4-8}$ Specifically, while naproxen $500 \mathrm{mg}$ twice daily caused a $70 \%$ reduction in gastric mucosal prostaglandin synthesis, rofecoxib $25 \mathrm{mg}$ and $50 \mathrm{mg}$ had no such effect..$^{10}$ Similarly, faecal blood loss and intestinal permeability, both thought to be useful markers of the potential of an NSAID to cause clinically significant gastrointestinal toxicity, ${ }^{11}{ }^{12}$ were increased in healthy subjects who received indomethacin $150 \mathrm{mg}$ or ibuprofen $250 \mathrm{mg}$, but not in subjects receiving rofecoxib $25 \mathrm{mg}$ or $50 \mathrm{mg} .^{13}{ }^{14}$

Endoscopic evaluation of the effect of rofecoxib on the gastrointestinal mucosa has further demonstrated its favourable gastrointestinal safety profile in comparison with non-selective NSAIDs. In healthy subjects treated for seven days, ibuprofen $2400 \mathrm{mg}$ and aspirin $2600 \mathrm{mg}$ were each associated with an increased incidence of erosions in healthy subjects in comparison with placebo, whereas rofecoxib $250 \mathrm{mg}$ (a supratherapeutic dose) given daily for seven days was not. ${ }^{15}$ Consistent with these results, two endoscopy studies in more than 1500 osteoarthritis (OA) patients over the age of 50 years showed that the incidence of ulcers over three months in patients receiving daily rofecoxib $25 \mathrm{mg}$ or $50 \mathrm{mg}$ was similar to that in patients on placebo and less than that in patients on

Abbreviations: COX, cyclooxygenase; NSAIDs, non-steroidal anti-inflammatory drugs; $O A$, osteoarthritis; PUBs, gastrointestinal perforations, ulcers, or bleeding episodes; RA, rheumatoid arthritis. 
ibuprofen 2400 mg. ${ }^{16}{ }^{17}$ Moreover, the clinical relevance of these endoscopic findings was demonstrated by an analysis of the results of eight phase II/III studies involving over 5400 OA patients. ${ }^{18}$ In this analysis, rofecoxib resulted in a significantly lower incidence of gastrointestinal perforations, ulcers, and bleeding episodes (PUBs) compared with non-selective NSAIDs. ${ }^{18}$

In addition to their role in the treatment of OA and pain, NSAIDs are also an important component of treatment for rheumatoid arthritis (RA). Because high and/or chronic dosing with NSAIDs, as well as concomitant use of corticosteroids, may put RA patients at greater risk for upper gastrointestinal ulcers compared with placebo, the safety of rofecoxib has also been scrutinised in this patient population. ${ }^{19-23} \mathrm{~A}$ large scale outcomes study of rofecoxib in RA patients (the VIGOR trial) showed that rofecoxib $50 \mathrm{mg}$ daily was associated with significantly fewer upper gastrointestinal events (symptomatic ulcers, perforations, bleeds, and obstructions) than naproxen $500 \mathrm{mg}$ twice daily, results similar to those observed in OA patients. ${ }^{24}$ An endoscopy study was conducted to examine further the gastrointestinal safety profile of rofecoxib compared with that of NSAIDs in RA patients.

\section{METHODS}

\section{Study population}

All patients participating in the study gave written informed consent and the study was conducted in conformance with applicable country or local ethics requirements. The study was conducted at 48 sites in 18 countries. Patients between the ages of 21 and 85 years were enrolled, with a confirmed clinical diagnosis of RA and a requirement of at least three months of NSAID therapy. Patients were excluded if they had an oesophageal, gastric, or duodenal ulcer, pyloric obstruction, or erosive oesophagitis at baseline endoscopy.

Patients were also excluded if they had any of the following: creatinine level $>2.0 \mathrm{mg} / \mathrm{dl}$; creatinine clearance $\leqslant 30 \mathrm{ml} / \mathrm{min}$ bleeding diathesis; requirement for anticoagulants, low dose aspirin, ticlopidine, or clopidogrel; unstable medical disease including current angina or congestive heart failure; previous upper gastrointestinal surgery; faecal occult blood; history of inflammatory bowel disease, history of myocardial infarction, coronary angioplasty, or coronary artery bypass graft within one year, cerebrovascular event or active hepatic disease within the past two years, or malignancy within the past five years. The study population included patients infected with Helicobacter pylori, a prior history of a gastroduodenal PUB, or the presence of gastroduodenal erosions at baseline endoscopy.

\section{Design}

This was a randomised, double blind, placebo controlled, parallel group study.

\section{Procedures}

Following a two week washout period from non-selective NSAIDs and any antisecretory or cytoprotective drugs, patients who met entry criteria underwent baseline upper gastrointestinal endoscopy and determination of $\mathrm{H}$ pylori status by gastric biopsy with a rapid urease test (CLOtest) and by histology. Patients were then randomised to one of three treatment groups: rofecoxib $50 \mathrm{mg}$ once daily, naproxen $500 \mathrm{mg}$ twice daily, or placebo, for 12 weeks. Matching placebo for each medication was used to maintain blinding. Treatment allocation was stratified by history of significant upper gastrointestinal disease (gastroduodenal ulcer or upper gastrointestinal haemorrhage or perforation), and each stratum was further stratified according to concomitant use of oral corticosteroids during the study. Stable doses of non-study antirheumatic medications other than NSAIDs and antisecretory or cytoprotective drugs were permitted, as were injectable or oral corticosteroids ( $\leqslant 10 \mathrm{mg}$ prednisone or equivalent daily). Rescue medications (acetaminophen/paracetamol for pain and Gelusil aluminum hydroxide/magnesium hydroxide/ simethicone (Warner-Lambert) for minor dyspepsia) were provided. Patients were prohibited from using the following medications throughout the study: $\mathrm{H}_{2}$ receptor antagonists, proton pump inhibitors, prostaglandin analogues, other gastroprotective agents, calcium containing antacids, anticoagulants, antiplatelet therapy, and cyclosporin.

Patients were evaluated clinically at study weeks 3, 6, 9, and 12. Endoscopy was performed at baseline, at study weeks six and 12 , at unscheduled discontinuation, and when deemed clinically necessary by the investigator. At endoscopy, the number and size of gastric and/or duodenal ulcers (defined as mucosal breaks with an unequivocal depth of at least $3 \mathrm{~mm}$ in the longest dimension) were recorded, and gastroduodenal mucosal erosions were counted. If an ulcer was detected, the patient was immediately discontinued from the study and underwent discontinuation procedures and ulcer treatment. Safety assessments also included physical examination and vital signs, laboratory parameters, and monitoring of clinical and laboratory adverse events throughout the study.

\section{Statistical analysis}

The cumulative incidence of gastric and/or duodenal ulcers $\geqslant 3 \mathrm{~mm}$ over 12 weeks was the primary end point of the study. A survival analysis was used to analyse time to event data for ulcer incidence, and the log rank test was used to compare the cumulative incidence of ulcers among treatment groups. Twelve week cumulative rates were estimated via KaplanMeier, and the Breslow-Crowley method ${ }^{25}$ was used to calculate 95\% confidence intervals (CIs); $95 \%$ CIs were also calculated for between treatment differences and the ratio of the 12 week cumulative rates for the prespecified comparisons. Although the study was not designed to compare rofecoxib with placebo, $\mathrm{p}$ values were calculated for comparisons with placebo.

Twelve week cumulative ulcer incidence rates of $7.5 \%$ for rofecoxib, $7.5 \%$ for placebo, and $25 \%$ for naproxen were assumed. The study had $98 \%$ power to detect such differences between rofecoxib or placebo versus naproxen, based on a two sided test with $\alpha=0.05$.

Assessment of treatment effect on ulcer incidence was made for patient subgroups to explore the consistency of effects across subgroups. These classifications were defined at baseline by the following: age ( $<65$ or $\geqslant 65$ years), sex, race (White or non-White), history of symptomatic PUB, $H$ pylori status, baseline number of gastric and/or duodenal erosions $(=0$ or $\geqslant 0)$, prior NSAID use, tobacco use, corticosteroid use, and geographical region (USA or international). A Cox proportional hazards model was used to test qualitative treatment by subgroup interactions.

Cumulative incidence of ulcers $\geqslant 5 \mathrm{~mm}$ over 12 weeks, and mean change from baseline number of erosions over 12 weeks were assessed as secondary end points. Continuous variables were analysed with an analysis of covariance model (with prespecified factors of treatment, gastrointestinal history, corticosteroid use, and baseline covariate where appropriate). Adverse event data were analysed by Fisher's exact test.

\section{RESULTS}

\section{Patient characteristics}

Figure 1 shows the disposition of patients throughout the study. Of the 660 patients enrolled at the randomisation visit, 509 completed the study. Nine, 11 , and 22 patients discontinued due to adverse experiences on placebo, rofecoxib, and naproxen, respectively, while 11 , four, and two patients, respectively, discontinued due to lack of efficacy. As shown in table 1 , there were no clinically meaningful differences among groups with regard to age, sex, race, history of gastrointestinal 


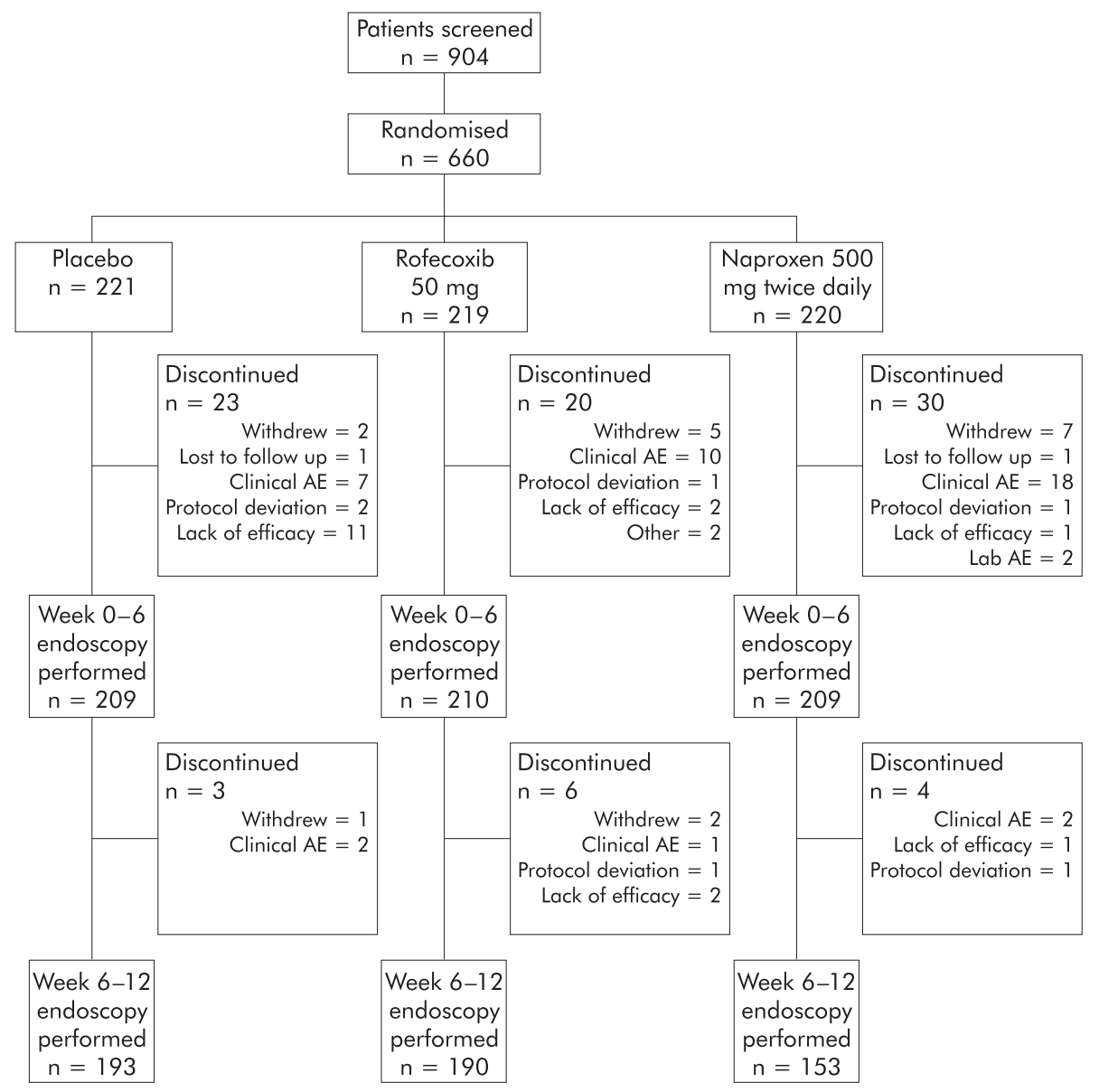

Figure 1 Study flow chart.

\begin{tabular}{|c|c|c|c|}
\hline Patient characteristic & $\begin{array}{l}\text { Placebo } \\
(n=221)\end{array}$ & $\begin{array}{l}\text { Rofecoxib } 50 \mathrm{mg} \\
(\mathrm{n}=219)\end{array}$ & $\begin{array}{l}\text { Naproxen } 500 \mathrm{mg} \\
\text { twice daily }(\mathrm{n}=220)\end{array}$ \\
\hline Female (\%) & 82 & 86 & 78 \\
\hline Mean age $(y)$ & 51 & 53 & 51 \\
\hline$\geqslant 65$ years $(\%)$ & 16 & 20 & 16 \\
\hline$\%$ from USA & 22 & 21 & 22 \\
\hline$\%$ White & 48 & 52 & 52 \\
\hline History of upper Gl events (PUBs) (\%) & 10 & 11 & 14 \\
\hline H pylori positive (\%) & 61 & 61 & 57 \\
\hline$\%$ with baseline gastroduodenal erosions & 11 & 13 & 14 \\
\hline Tobacco use (\%) & 38 & 34 & 40 \\
\hline Corticosteroids (\%) & 61 & 56 & 59 \\
\hline Prior NSAID use (\%) & 70 & 68 & 57 \\
\hline
\end{tabular}

events, $H$ pylori status, tobacco use, presence of gastroduodenal erosions, or prior NSAID use.

\section{Incidence of ulcers and erosions}

The six and 12 week incidences of ulcers $\geqslant 3 \mathrm{~mm}$ are shown in fig 2. The 12 week cumulative incidence of gastroduodenal ulcers $\geqslant 3 \mathrm{~mm}$ in patients on naproxen $500 \mathrm{mg}$ twice daily $(25.5 \%)$ was significantly greater than that in patients on rofecoxib $50 \mathrm{mg}(6.8 \%$; between treatment difference $18.7 \%$ (95\% CI $11.7 \%, 25.7 \%) ; p \leqslant 0.001)$ or placebo $(2.9 \%$; difference $22.6 \%(95 \%$ CI $16.1 \%, 29.1 \%) ; \mathrm{p}<0.001)$ whereas the incidence in patients on rofecoxib did not differ significantly from that in patients on placebo $(2.9 \% ; p=0.066)$. Findings for ulcers $\geqslant 5 \mathrm{~mm}$ were similar and are shown in fig 3 . The 12 week cumulative incidence of ulcers $\geqslant 5 \mathrm{~mm}$ was $2.9 \%, 5.3 \%$, and $17.1 \%$ in patients on placebo, rofecoxib, and naproxen, respectively (difference for naproxen $v$ rofecoxib $(95 \% \mathrm{CI}$ ) $11.8 \%(5.7 \%, 18.0 \%), \mathrm{p} \leqslant 0.001$; difference for naproxen $v$ placebo $14.2 \%, p \leqslant 0.001)$. The incidence in the rofecoxib group did not differ significantly from that in the placebo group $(2.9 \% ; p=0.210)$. As shown in fig 4 , the least squares mean change from baseline in the number of erosions was significantly higher in patients on naproxen versus those on rofecoxib (difference $(95 \% \mathrm{CI}) 4.05(93.37,4.73)$; $\mathrm{p}<0.001$ ) and in patients on naproxen versus patients on placebo (difference $(95 \% \mathrm{CI}) 4.41(3.73,5.08) ; \mathrm{p} \leqslant 0.001)$. There was no significant difference between patients on placebo and patients on rofecoxib.

A similar pattern of treatment effects was seen when gastric and duodenal ulcers were examined separately. The cumulative incidence of gastric ulcers $\geqslant 3 \mathrm{~mm}$ at 12 weeks was $2.0 \%$ for placebo, $5.9 \%$ for rofecoxib, and $22.1 \%$ for naproxen. The 


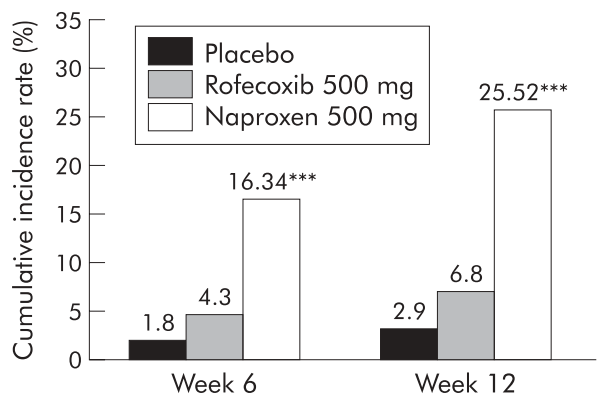

Figure 2 Cumulative incidence rate (\%) of gastroduodenal ulcers $\geqslant 3 \mathrm{~mm}$ (intention to treat) in the placebo, rofecoxib $50 \mathrm{mg}$, and naproxen $500 \mathrm{mg}$ twice daily groups. ${ }^{* *} \mathrm{*}<<0.001$ for naproxen versus rofecoxib or placebo.

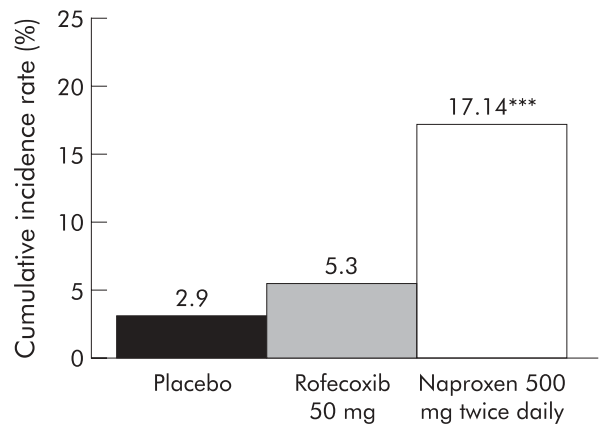

Figure 3 Cumulative incidence rate (\%) of gastroduodenal ulcers $\geqslant 5 \mathrm{~mm}$ at week 12 (intention to treat) in the three groups. ${ }^{* * *} p<0.001$ for naproxen versus rofecoxib or placebo.

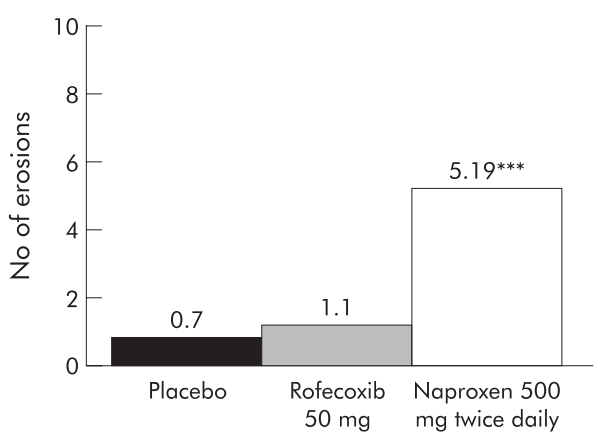

Figure 4 Least squares mean change from baseline number of gastroduodenal erosions at week 12 (intention to treat) in the three groups. ${ }^{* * *} p<0.001$ for naproxen versus rofecoxib or placebo.

cumulative incidence of duodenal ulcers $\geqslant 3 \mathrm{~mm}$ at 12 weeks was $0.9 \%$ for placebo, $1.0 \%$ for rofecoxib, and $5.2 \%$ for naproxen.

\section{Risk modifiers}

Between treatment comparisons for ulcer ( $\geqslant 3 \mathrm{~mm}$ ) incidence in subgroups defined by baseline patient characteristics were found to be generally consistent across all levels of all subgroups. Age $\geqslant 65$ years, White race, and presence of prior gastrointestinal history were risk factors for gastroduodenal ulcers, as demonstrated by statistically significant main effects. There was no significant main effect of $H$ pylori status $(\mathrm{p}=0.077)$ and no significant interaction between $H$ pylori status and treatment $(p=0.500)$. The cumulative incidence of ulcers $\geqslant 3 \mathrm{~mm}$ at 12 weeks in $H$ pylori negative patients was $3.6 \%$ for placebo, $3.9 \%$ for rofecoxib, and $33.3 \%$ for naproxen. In $H$ pylori positive patients, the cumulative incidence of ulcers $\geqslant 3 \mathrm{~mm}$ at 12 weeks was $2.3 \%$ for placebo, $8.3 \%$ for rofecoxib, and $17.9 \%$ for naproxen.

\section{Tolerability}

Table 2 summarises the tolerability assessments. There was no significant difference among treatment groups in the overall incidence of adverse events, although the incidence of drug related adverse events was higher in patients on naproxen and those on rofecoxib compared with those on placebo $(p=0.002$ for naproxen $v$ placebo; $\mathrm{p}=0.030$ for rofecoxib $v$ placebo). Patients taking naproxen had a significantly higher rate of discontinuations due to an adverse event compared with the placebo group $(\mathrm{p}=0.036)$.

Comparison of the incidence of serious clinical adverse experiences among treatment groups showed no significant differences $(2.7 \%$ for placebo, $1.8 \%$ for rofecoxib, and $4.1 \%$ for naproxen) (table 2). One death was reported among patients taking naproxen (hepatic and multiple organ failure in a patient discovered to be seropositive for hepatitis B). This was considered definitely not related to the study drug by the investigator. No serious laboratory adverse events were reported, and rates of all laboratory adverse experiences were generally similar among treatment groups $(12.7 \%$ in patients on placebo, $14.2 \%$ in patients on rofecoxib, and $18.3 \%$ in patients on naproxen) except for slightly more numerous reports of decreases in haematocrit and haemoglobin in patients taking naproxen compared with the two other groups.

The three adverse events most commonly reported over the entire study were epigastric discomfort, dyspepsia, and heartburn, each of which was reported in at least $5 \%$ of patients in each treatment group. No significant difference was observed among treatment groups for the incidence of dyspepsia $(6.3 \%$ on placebo, $10.0 \%$ on rofecoxib, and $7.3 \%$ on naproxen) or heartburn $(5.0 \%$ on placebo, $9.1 \%$ on rofecoxib, and $7.3 \%$ on naproxen); however, the rofecoxib group $(9.1 \%)$ and the placebo group (8.6\%) both had significantly lower incidences of epigastric discomfort compared with the naproxen group ( $17.3 \% ; \mathrm{p} \leqslant 0.016$ for rofecoxib or placebo $v$ naproxen). The percentages of patients who discontinued because of an adverse event involving the digestive system or abdominal pain were $0.9 \%$ on placebo, $3.7 \%$ on rofecoxib, and $6.8 \%$ on naproxen. The difference between the naproxen and placebo groups was statistically significant $(5.9 \% ; p=0.001)$ but the difference between the rofecoxib and placebo groups was not $(p=0.062)$. There were seven PUBs (one patient on placebo, two patients on rofecoxib, and four patients on naproxen).

Because COX inhibition has known renal and vascular effects, analyses were prespecified for comparisons between groups for adverse experiences involving hypertension, oedema, or congestive heart failure (table 3). The reported incidences of hypertension were $2.3 \%$ for the placebo group, $6.4 \%$ for the rofecoxib group, and $0.9 \%$ for the naproxen group, and lower extremity oedema was reported for $1.8 \%$ of patients on placebo, $1.4 \%$ of patients on rofecoxib, and $0 \%$ of patients on naproxen. No patient discontinued treatment with the study drug due to either hypertension or lower extremity oedema. Likewise, there were no between treatment group differences observed for the incidences of congestive heart failure adverse events, which were reported for one patient in the study (rofecoxib group). This patient's event was considered not serious and not related to study drug by the investigator.

\section{DISCUSSION}

In the present study, rofecoxib $50 \mathrm{mg}$ (twice the recommended dose for the treatment of RA) resulted in significantly fewer endoscopically detected gastroduodenal ulcers $\geqslant 3 \mathrm{~mm}$ at 12 weeks compared with naproxen $500 \mathrm{mg}$ twice daily. This was also true for ulcers $\geqslant 5 \mathrm{~mm}$, which some clinical experts have 
Table 2 Summary of safety data (\% of patients)

\begin{tabular}{|c|c|c|c|}
\hline & $\begin{array}{l}\text { Placebo } \\
(n=221)\end{array}$ & $\begin{array}{l}\text { Rofecoxib } 50 \mathrm{mg} \\
(\mathrm{n}=219)\end{array}$ & $\begin{array}{l}\text { Naproxen } 500 \mathrm{mg} \\
\text { twice daily }(\mathrm{n}=220)\end{array}$ \\
\hline One or more clinical adverse events & 61.1 & 62.1 & 66.4 \\
\hline Drug related adverse event* & 25.8 & $35.6+$ & $39.5 t$ \\
\hline Serious adverse event & 2.7 & 1.8 & 4.1 \\
\hline Discontinued due to an adverse event & 4.1 & 5.0 & $9.1+$ \\
\hline
\end{tabular}

Table 3 Percentages of patients with adverse events of interest for selective COX-2 inhibitors

\begin{tabular}{llll}
\hline & $\begin{array}{l}\text { Placebo } \\
(\mathrm{n}=221)\end{array}$ & $\begin{array}{l}\text { Rofecoxib 50 } \mathrm{mg} \\
(\mathrm{n}=219)\end{array}$ & $\begin{array}{l}\text { Naproxen 500 mg } \\
\text { twice daily (n=220) }\end{array}$ \\
\hline Hypertension & 2.3 & 6.4 & 0.9 \\
Discontinued due to hypertension & 0.0 & 0.0 & 0.0 \\
Lower extremity oedema & 1.8 & 1.4 & 0.0 \\
Discontinued due to lower extremity oedema & 0.0 & 0.0 & 0.0 \\
Congestive heart failure & 0.0 & 0.5 & 0.0 \\
Discontinued due to congestive heart failure & 0.0 & 0.5 & 0.0 \\
Haemoglobin decreased & 1.4 & 3.7 & 5.5 \\
Haematocrit decreased & 2.3 & 4.1 & 7.8 \\
\hline
\end{tabular}

argued may be more clinically meaningful than those $\geqslant 3$ $\mathrm{mm} .{ }^{26}$ The latter findings are particularly compelling in view of the fact that ulcers $\geqslant 3 \mathrm{~mm}$ but $<5 \mathrm{~mm}$ resulted in immediate patient discontinuation, a stipulation which may have interrupted the development of some larger ulcers $(\geqslant 5 \mathrm{~mm})$ and led to a conservative comparison with rofecoxib. Despite this, a significant advantage with rofecoxib $50 \mathrm{mg}$ persisted compared with naproxen $500 \mathrm{mg}$ twice daily. Rofecoxib $50 \mathrm{mg}$ also demonstrated significantly lower increases in the number of gastroduodenal erosions at 12 weeks compared with naproxen $500 \mathrm{mg}$ twice daily.

A prior history of PUBs was observed to be a positive risk factor for ulcer, as reported previously. ${ }^{19} 2327$ Patients with a prior history of PUBs are known to have an increased risk of ulceration when taking NSAIDs. ${ }^{28-30}$ Age $\geqslant 65$ years and White race ( $v$ non-white) were also identified as risk factors for the development of gastroduodenal ulceration in this study. While older age has been previously identified as a potential risk factor for the development of endoscopic ulcers in patients with $\mathrm{RA}$, race has not been previously identified as a factor in other studies. The clinical significance of this finding is unclear. However, the advantage of rofecoxib $50 \mathrm{mg}$ over naproxen 500 mg twice daily was maintained in all these subgroups. H pylori status was not a risk factor for the development of ulcers in this study.

There were no statistically significant differences in the incidence of ulcers or erosions for the comparison of rofecoxib with placebo whereas naproxen showed a significant increase relative to placebo on all measures. There was a numerical increase in ulcers and erosions for rofecoxib relative to placebo, raising the possibility that this dose of rofecoxib may slightly increase ulcer rates in RA patients, unlike findings previously reported in OA. A previous combined analysis of OA endoscopy studies established statistical equivalence to placebo for a daily dose of $25 \mathrm{mg}$, but not for $50 \mathrm{mg} .{ }^{16}$ This suggests that the numerical increase versus placebo seen in this study may have been less pronounced (or non-existent) at a lower dose.

Interestingly, the ulcer incidence rate in patients on placebo (2.9\%) was lower than the incidence rates previously observed in two studies of similar design which assessed the incidence of gastroduodenal ulceration over 12 weeks in patients with
OA. ${ }^{1631}$ These previous studies showed placebo ulcer incidences over 12 weeks of $9.92 \%$ and $5.10 \%$, respectively. The significant variability in the incidence of endoscopic ulcers in patients taking placebo in these individual trials is consistent with the conclusion that small between treatment group differences in rates of endoscopic ulcer may not reflect clinically significant differences in drug effect. By contrast, the highly statistically significant differences from the naproxen $500 \mathrm{mg}$ twice daily group in ulcer incidence in both the placebo and rofecoxib $50 \mathrm{mg}$ groups are consistent with the results of a large clinical outcomes trial in RA patients that demonstrated a significant decrease in the incidence of clinical events of PUBs with rofecoxib $50 \mathrm{mg}$ (a higher dose than recommended) compared with naproxen $500 \mathrm{mg}$ twice daily (a standard dose) ${ }^{24}$ This large study also compared a standard dose of naproxen with a dose of rofecoxib that is higher than recommended.

Rofecoxib $50 \mathrm{mg}$ demonstrated a favourable safety profile compared with naproxen $500 \mathrm{mg}$ twice daily and was well tolerated over the 12 week treatment period. The overall incidence of clinical and laboratory or serious adverse experiences was generally similar between the rofecoxib $50 \mathrm{mg}$, naproxen $500 \mathrm{mg}$ twice daily, and placebo groups. Naproxen had the highest rate of drug related adverse experiences and placebo had the lowest rate. The rate of discontinuation due to adverse experiences was numerically similar between the rofecoxib $50 \mathrm{mg}$ and placebo groups whereas the incidence of discontinuation due to adverse experiences was significantly greater in patients on naproxen $500 \mathrm{mg}$ twice daily compared with those on placebo

The adverse event profile was also supportive of better gastrointestinal tolerability for rofecoxib $50 \mathrm{mg}$ than for naproxen $500 \mathrm{mg}$ twice daily. Naproxen resulted in a significantly increased incidence of discontinuations due to adverse experiences of the digestive system or of abdominal pain whereas the incidence of these adverse experiences in patients on rofecoxib was less than that in patients on naproxen and not significantly different from placebo. Due to the small sample size and low incidence of upper gastrointestinal PUBs in this study, a significant difference in the incidence between treatment groups was not expected and therefore these data were not analysed. Data have previously 
been published showing that upper gastrointestinal PUBs are reduced with rofecoxib compared with non- selective NSAIDs. ${ }^{18}{ }^{24}$ Previous data have also shown a reduced incidence of falls in haemoglobin with rofecoxib and celecoxi, ${ }^{24}{ }^{30}$ probably as a result of reduced whole gut blood loss. ${ }^{13}$ The size of our study means that differences were not statistically significant.

Consistent with previous studies, ${ }^{32-34}$ rofecoxib $50 \mathrm{mg}$ was associated with a small increase in the incidence of physician reported adverse events of hypertension. A review of all hypertensive adverse experiences showed that these were generally of minor clinical impact and that most affected patients had pre-existing diagnoses of hypertension. No patient discontinued due to adverse experiences of hypertension; all patients continued on study drug and either had spontaneous resolution of their adverse experience or had adjustment made to their non-study medications such that the hypertension was treated. No association between hypertension adverse experiences and untoward outcomes (for example, unstable angina, myocardial infarction, or cerebrovascular events) was observed. In the group as a whole, mean changes in blood pressure showed that changes in systolic or diastolic readings occurred early in the course of therapy and tended to be transient (resolving on treatment). It should be noted that these results were observed with a dose of rofecoxib that is twice the dose recommended for chronic treatment of RA.

In summary, the findings of this study demonstrated that treatment with rofecoxib $50 \mathrm{mg}$ once daily was well tolerated in RA patients and resulted in lower incidences of endoscopically detected gastroduodenal ulcers and erosions compared with naproxen $500 \mathrm{mg}$ twice daily.

\section{APPENDIX}

Participating investigators of the Rofecoxib Rheumatoid Arthritis Endoscopy Study Group were: Spyros J Aslanides, Humeira Badsha, Donald R Campbell, Lucio Capurso, M Oswaldo Castañeda J, Maria Antonieta Tuna Castro, John P Cello, Roberto O Chiprut, Yun S Choe, Lai Kam Chuen, José Antonio Maldonado Cocco, David A Cooley, Michael S Doyle, Mario Alberto Garza Elizondo, David Fitz-Patrick, Mark C Goldberg, Dahlia Pilar Riachi González, Christopher John Hawkey, Josef Hermann, Ruben Dario Mantilla Hernandez, Jon I Isenberg, Jonathan Kay, George Koval, Loren Laine, Frank Lanza, Steven Mathews, Brent Lee Mitchell, Franco Montrone, John V Murray, Vijay Narayen, Nicholas J Nickl, Peter M Pardoll, Giampiero Pasero, Eric Peters, Geraldo da Rocha Castelar Pinheiro, Francesco Porzio, Franz Rainer, JeanPierre Raufman, Guido Rovetta, Ricardo Sáenz, Peter Seideman, Umedchandra K Shah, Martin L Throne, Raymond Tobias, James Torosis, Ana Maria Flores Torterolo, Margarita Ugaz Villacorta, Carlos Alberto von Muhlen, John M Wo, Hasan Yazici, Neville David Yeomans, Salam F Zakko.

\section{Authors' affiliations}

C J Hawkey, University Hospital, Nottingham, United Kingdom L Laine, USC School of Medicine, Los Angeles, CA, USA T Simon, H Quan, S Shingo, J Evans, Merck Research Laboratories, West Point, PA, USA

\section{REFERENCES}

1 Wolfe MM, Lichtenstein DR, Singh G. Gastrointestinal toxicity of nonsteroidal antiinflammatory drugs. N Engl I Med 1999-340:1888-99.

2 Loebl DH, Craig R, Culic D, et al. Gastrointestinal blood loss: effect of aspirin, fenoprofen, and acetaminophen in rheumatoid arthritis as determined by sequential gastroscopy and radioactive fecal markers. JAMA 1977;237:976-81.

3 Hawkey CJ, Jackson L, Harper SE, et al. The gastrointestinal safety profile of rofecoxib, a highly selective inhibitor of cyclooxygenase-2, in profile of rofecoxib, a highly selective inhibitor

4 Cannon GW, Caldwell JR, Holt $P$, et al. Rofecoxib, a specific inhibitor of cyclooxygenase 2, with clinical efficacy comparable with that of diclofenac sodium: results of a one-year, randomized, clinical trial in patients with osteoarthritis of the knee and hip. Rofecoxib Phase III Protocol 035 Study Group. Arthritis Rheum 2000;43:978-87.

5 Day $\mathbf{R}$, Morrison $B$, Luza $M$, et al. A randomized trial of the efficacy and tolerability of the COX-2 inhibitor rofecoxib vs. ibuprofen in patients with osteoarthritis. Rofecoxib/lbuprofen Comparator Study Group. Arch Intern Med 2000;160:1781-7.

6 Ehrich EW, De Dallob A, Lepeliere I, et al. Characterization of rofecoxib as a cyclooxygenase-2 isoform inhibitor and demonstration of analgesia in the dental pain model. Clin Pharmacol Ther 1999:65:336-47.

7 Merck \& Co., Inc. Vioxx (Rofecoxib Tablets and Oral Suspension). Physicians Desk Reference. Montvale, NJ: Medical Economics Company, 2000; 1912-15.

8 Morrison BW, Daniels SE, Kotey P, et al. Rofecoxib, a specific cyclooxygenase-2 inhibitor, in primary dysmenorrhea: a randomized controlled trial. Obstet Gynecol 1999:94:504-8.

9 Wright N, Garlick N, Calder N, et al. Evidence that the COX-2 specific inhibitor rofecoxib at $50 \mathrm{mg}$ spares gastric mucosal prostaglandin synthesis in humans. Gut 1999;45(suppl V):A25.

10 Cryer B, Gottesdiener K, Gertz B, et al. In vivo effects of rofecoxib, a new cyclooxygenase (COX)-2 inhibitor, on gastric mucosal prostaglandin (PG) and serum thromboxane B2 (TXB2) synthesis in healthy humans (abstract). Am J Gastroenterol 1999:91:1907.

11 Bjarnason I, Zanelli G, Smith T, et al. The pathogenesis and consequence of nonsteroidal anti-inflammatory drug induced small intestinal inflammation in man. Scand J Rheumatol 1987;64/suppl 69): 55-62.

12 Ridolfo, AS, Crabtree, RE, Johnson, DW, et al. Gastrointestinal microbleeding: comparisons between benoxaprofen and other nonsteroidal anti-inflammatory agents. J Rheumatol 1980;7/suppl 6): $36-47$.

13 Hunt R, Bowen B, Mortensen E, et al. A randomized trial measuring fecal blood loss after treatment with rofecoxib, ibuprofen, or placebo in healthy subjects. Am J Med 2000;109:201-6.

14 Sigthorsson G, Crane R, Simon T, et al. Cox-2 inhibition with rofecoxib does not increase intestinal permeability in healthy subjects. A double-blind, crossover study comparing rofecoxib with placebo and indomethacin. Gut 2000;47:527-32.

15 Lanza FL, Rack MF, Simon TJ, et al. Specific inhibition of cyclooxygenase-2 with MK-0966 is associated with less gastroduodenal damage than either aspirin or ibuprofen. Aliment Pharmacol Ther $1999 ; 13: 761-7$.

16 Hawkey C, Laine L, Simon T, et al. A randomized, double-blinded comparison of the effect of rofecoxib (a drug specifically inhibiting COX-2), ibuprofen, or placebo on the gastroduodenal mucosa of osteoarthritis patients. Arthritis Rheum 2000;43:370-7.

17 Laine L, Harper S, Simon T, et al. A randomized trial comparing the effect of rofecoxib, a cyclooxygenase 2-specific inhibitor, with that of ibuprofen on the gastroduodenal mucosa of patients with osteoarthritis. Gastroenterology 1999:117:776-83.

18 Langman $M$, Jensen DM, Watson DJ, et al. Adverse upper gastrointestinal effects of rofecoxib compared with NSAID's. JAMA 1999;282:1929-33.

19 Fries JF. NSAID gastropathy: the second most deadly rheumatic disease? Epidemiology and risk appraisal. J Rheumatol 1991;18/suppl 28):6-10.

20 Seibert K, Zhang Y, Leahy K, et al. Pharmacological and biochemical demonstration of the role of cyclooxygenase 2 in inflammation and pain Proc Natl Acad Sci U S A 1994;91:12013-7.

21 Vane J. Towards a better aspirin. Nature 1994;367:215-16.

22 Masferrer JL, Zweifel BS, Manning PT, et al. Selective inhibition of inducible cyclooxygenase 2 in vivo is antiinflammatory and nonulcerogenic. Proc Natl Acad Sci U S A 1994:91:3228-32.

23 Gabriel SE, Jaakkimainen L, Bombardier C. Risk for serious gastrointestinal complications related to use of nonsteroidal anti-inflammatory drugs. Ann Intern Med 1991;115:787-96.

24 Bombardier C, Laine L, Reicin A, et al for the VIGOR Study Group. Comparison of upper gastrointestinal toxicity of rofecoxib and naproxen in patients with rheumatoid arthritis. N Engl J Med 2000:343:1520-8.

25 Breslow EN, Crowley J. A large sample study of the life table and product limit estimates under random censorship. Ann Stat 1974;2:437-53.

26 Graham DY. High-dose famotidine for prevention of NSAID ulcers. Gastroenterology 1997;112:2143-5.

27 Taha AS, Sturrock RD, Russell RI. Mucosal erosions in long term non-steroidal anti- inflammatory drug users: predisposition to ulceration and relation to Helicobacter pylori. Gut 1995;36:334-6.

28 Graham DY, White RH, Moreland LW, et al. Duodenal and gastric ulcer prevention with misoprostol in arthritis patients taking NSAIDs. Ann Intern Med 1993;119:257-62

29 Griffin MR, Piper JM, Daugherty JR, et al. Nonsteroidal anti-inflammatory drug use and increased risk for peptic ulcer disease in elderly persons. Ann Intern Med 1991:114:257-63.

30 Silverstein FE, Graham DY, Senior JR, et al. Misoprostol reduces serious gastrointestinal complications in patients with rheumatoid arthritis receiving nonsteroidal anti-inflammatory drugs. Ann Intern Med $1995 ; 123: 241-9$

31 Hawkey CJ, Laine L, Harper SE, et al for the Rofecoxib Osteoarthritis Endoscopy Mutinational Study Group. Influence of risk factors on endoscopic and clinical ulcers in patients taking rofecoxib or ibuprofen in two randomized controlled trials. Aliment Pharmacol Ther 2001; 15:1593-601. 
32 Saag K, van-der-Heijde D, Fisher C, et al. Rofecoxib, a new cyclooxygenase 2 inhibitor, shows sustained efficacy, comparable with other nonsteroidal anti-inflammatory drugs: a 6 -week and a 1 -year tria in patients with osteoarthritis. Arch Fam Med 2000;9:1 124-34

33 Truitt KE, Lee M, DeTora LM, et al. Results of a pivotal (phase III) placebo and active comparator controlled efficacy trial of rofecoxib 12.5 and $25 \mathrm{mg}$ in adult patients with rheumatoid arthritis (RA). Arthritis Rheum 2001:44(9 suppl):S369.

34 Truitt KE, Guesens PP, DeTora LM, et al. Results of a pivotal (phase III) placebo and active comparator controlled efficacy trial of rofecoxib 25 and $50 \mathrm{mg}$ in adult patients with rheumatoid arthritis (RA). Ann Rheum Dis 2001;60(suppl 1):161

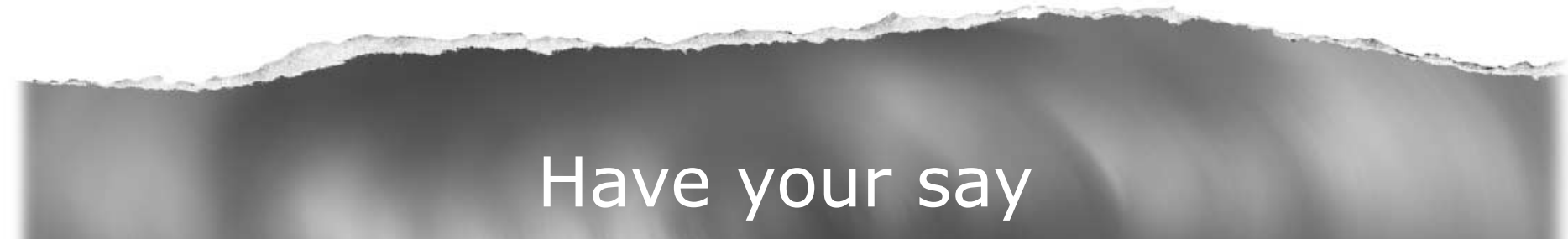

eLetters

If you wish to comment on any article published in Gut you can send an eLetter using the eletters link at the beginning of each article. Your response will be posted on Gut online within a few days of receipt (subject to editorial screening).

www.gutjnl.com 


\section{PostScript}

\section{LETTERS}

If you have a burning desire to respond to a paper published in Gut, why not make use of our "rapid response" option?

Log onto our website (www.gutinl.com), find the paper that interests you, and send your response via email by clicking on the "eletters" option in the box at the top right hand corner.

Providing it isn't libellous or obscene, it will be posted within seven days. You can retrieve it by clicking on "read eletters" on our homepage.

The editors will decide as before whether to also publish it in a future paper issue.

\section{$H$ pylori infection and reflux oesophagitis}

We read with considerable interest the paper by Kuipers et al (Gut 2004;53:12-20) which found no significant adverse impact on the severity of reflux disease or its control after two years of omeprazole therapy following $H$ pylori eradication, during which time gastritis largely healed. In the commentary by McColl (Gut 2004;53:5-7), it is stated that although published data are conflicting, Schwizer et al reported improvement in reflux symptoms following $H$ pylori treatment. ${ }^{1}$ Our preliminary published data, ${ }^{2}$ which are in accordance with those of Schwizer and colleagues, consisted of a small cohort of 69 patients with gastro-oesophageal reflux disease (GORD) and irritable bowel syndrome (IBS). Forty patients were treated with omeprazole $(20 \mathrm{mg} /$ day $)$ plus trimebutine $(600 \mathrm{mg} /$ day $)$ for three months (group A) and 29 were treated with omeprazole $(20 \mathrm{mg} /$ day) as monotherapy for an equal period of time (group B). Inclusion and exclusion criteria matched those of Kuipers et al. Upper and lower gastrointestinal endoscopic, histological, and clinical evaluations were made at baseline. Furthermore, upper gastrointestinal evaluation was repeated three months post-treatment. At baseline, oesophagitis, confirmed by histology, and the histological presence of $H$ pylori were observed in $67.5 \%$ and $62.1 \%$ and in $80 \%$ and $82.8 \%$ of groups $\mathrm{A}$ and $\mathrm{B}$ of patients, respectively. All $H$ pylori positive patients received eradication treatment, as analysed in Kuipers et al's paper. The eradication rate was observed in $84 \%$ of $H$ pylori/positive patients in group A and in $83 \%$ of $\mathrm{H}$ pylori/ positive patients in group B. Three months post-treatment, there was a significant improvement in GORD $(\mathrm{p}=0.003)$, IBS symptoms $(\mathrm{p}<0.0001)$, and oesophagitis $(\mathrm{p}=0.029)$ in group A compared with group B. At baseline, all $24 \mathrm{H}$ pylori/positive patients who received omeprazole and the eradication regimen had GORD symptoms and 15 $(62.5 \%)$ had histologically proven oesophagitis. Three months post-treatment, GORD was present in $12(50 \%)$ patients $(\mathrm{p}<0.0001)$ and oesophagitis in nine $(37.5 \%)(p>0.05)$. As improvement in oesophagitis did not reach a statistically significant level, our study was continued and results are shown in table 1 (unpublished data). All $45 \mathrm{H}$ pylori/positive patients who received omeprazole and the eradication regimen had GORD and 29 $(64.4 \%)$ had oesophagitis at baseline. Three months post-treatment, $22 \quad(48.9 \%)$ had GORD symptoms $(\mathrm{p}<0.00001)$ and 18 $(40 \%)$ had oesophagitis $(p=0.03)$ (Wilcoxon's rank sum test, two tailed p values; data not shown in table 1). There was a statistically better response in patients who also received trimebutine.

In our preliminary study, Barrett's oesophagus was observed in eight $(20 \%)$ of 40 and in five $(17.2 \%)$ of 29 patients in groups $\mathrm{A}$ and $\mathrm{B}$, respectively, similar to that $(24.3 \%)$ observed by Kuipers et al. As there is an increased prevalence of IBS in patients with GORD, ${ }^{3}$ it would be interesting to know how many of the patients in Kuipers et al's study had symptoms suggestive of IBS, and if their regimen had results similar to ours.

Our data show that $H$ pylori is frequent in GORD and may contribute to the pathogenesis of GORD by several mechanisms. ${ }^{2}$ Also, we propose that the increasing prevalence of GORD may be partially explained not just by the decrease in prevalence of $H$ pylori infection, as suggested by McColl (Gut 2004;53:5-7), but rather by healing of $H$ pylori associated peptic ulcer disease, which coexists with GORD.. ${ }^{4}$ Thus eliminating peptic ulcer disease unmasks GORD. ${ }^{5}$

In our latest unpublished data, 18 (48.6\%) of 37 patients, in whom $H$ pylori was eradicated, had reflux symptoms on omeprazole compared with four $(50 \%)$ of eight patients in whom $H$ pylori was not eradicated. Although the latter group was too small to draw definite conclusions, it seems that eradicating $H$ pylori did not make GORD more difficult to control. While the editorial advocates that $H$ pylori eradication makes it more difficult to achieve long term control of GORD with omeprazole therapy, we suggest that $H$ pylori eradication leads to better control of GORD symptoms and improves oesophagitis.

J Kountouras, C Zavos, D Chatzopoulos

Department of Medicine, Second Medical Clinic,

Aristotle University of Thessaloniki, Ippokration Hospital, Thessaloniki, Greece

Correspondence to: $\mathrm{Dr} J$ Kountouras, 8 Fanariou St, Byzantio, 551 33, Thessaloniki, Macedonia, Greece; jannis@med.auth.gr

\section{References}

Schwizer W, Thumshirn M, Dent J, et al. Helicobacter pylori and symptomatic relapse of gastro-oesophageal reflux disease: a randomised controlled trial. Lancet 2001;357:1738-42.

2 Kountouras J, Chatzopoulos D, Zavos C, et al. Efficacy of trimebutine therapy in patients with gastroesophageal reflux disease and irritable bowel syndrome. Hepatogastroenterology 2002;49:193-7.

3 Pimentel M, Rossi F, Chow EJ, et al. Increased prevalence of irritable bowel syndrome in patients with gastroesophageal reflux. J Clin Gastroenterol 2002; $34: 221-4$

4 O'Connor HJO, McGee C, Mehana N, et al. Prevalence of gastroesophageal reflux disease (GERD) in $\mathrm{H}$. pylori-positive peptic ulcer disease and the impact of eradication therapy. Gastroenterology 1998; 114:G1001.

5 Ecclissato C, Carvalho AF, Ferraz JG et al. Prevalence of peptic lesions in asymptomatic, healthy volunteers. Dig Liver Dis $2001 ; 33: 403-6$

Table 1 Patient profile prior to and after the therapeutic regimens and comparisons between the two groups

\begin{tabular}{|c|c|c|c|c|c|c|c|c|c|c|c|c|c|c|}
\hline & \multicolumn{5}{|c|}{$\begin{array}{l}\text { Group } A(n=92) \text { (omeprazole plus } \\
\text { trimebutine) }\end{array}$} & \multicolumn{5}{|c|}{ Group B ( $n=56$ ) (omeprazole) } & \multicolumn{4}{|c|}{ Significance (p) } \\
\hline & \multicolumn{2}{|l|}{ Prior } & \multicolumn{3}{|c|}{ After 3 months } & \multicolumn{2}{|l|}{ Prior } & \multicolumn{3}{|c|}{ After 3 months } & \multicolumn{2}{|l|}{$A \vee B$} & \multirow{2}{*}{$\begin{array}{l}\text { Alb v } \\
\text { B lb }\end{array}$} & \multirow{2}{*}{$\frac{A 2 v B 2}{\text { After }}$} \\
\hline & $\begin{array}{l}A 1 \\
(n=73)\end{array}$ & $\begin{array}{l}A 2 \\
(n=19)\end{array}$ & $\begin{array}{l}\text { Ala } \\
(n=12)\end{array}$ & $\begin{array}{l}A 1 b \\
(n=61)\end{array}$ & $\begin{array}{l}\text { A2 } \\
(n=19)\end{array}$ & $\begin{array}{l}B 1 \\
(n=45)\end{array}$ & $\begin{array}{l}\text { B2 } \\
(n=11)\end{array}$ & $\begin{array}{l}\text { Bla } \\
(n=8)\end{array}$ & $\begin{array}{l}B 1 b \\
(n=37)\end{array}$ & $\begin{array}{l}\text { B2 } \\
(n=11)\end{array}$ & Prior & After & & \\
\hline $\begin{array}{l}\text { GORD } \\
\text { symptoms }\end{array}$ & 73 & 19 & 5 & 10 & 3 & 45 & 11 & 4 & 18 & 7 & NS & $<0.001$ & $<0.005$ & $<0.025$ \\
\hline Oesophagitis & 51 & 12 & 5 & 10 & 3 & 29 & 7 & 2 & 16 & 5 & NS & $<0.01$ & $<0.01$ & \\
\hline IBS symptoms & 73 & 19 & 2 & 7 & 3 & 45 & 11 & 4 & 23 & 7 & NS & $<0.001$ & $<0.001$ & $<0.025$ \\
\hline
\end{tabular}

$\mathrm{p}$ values between the two groups were calculated using the $\chi^{2}$ test with Yates' correction (two tailed $\mathrm{p}$ values)

Group A, patients were assigned to three months of omeprazole plus trimebutine treatment; group B, patients were assigned to three months of omeprazole monotherapy; groups $\mathrm{Al}, \mathrm{BI}, \mathrm{H}$ pylori positive patients prior to treatment assigned to omeprazole plus trimebutine or omeprazole alone, respectively; groups $A 1 a, B 1 a$, patients from groups $A 1$ and $B 1$, respectively, who remained $H$ pylori positive after the eradication regimen; groups $A 1 b, B 1 b$, patients from groups $A 1$ and $B 1$, respectively, in whom $H$ pylori infection was eradicated; groups $A 2, B 2, H$ pylori negative patients prior to and after treatment with omeprazole plus trimebutine or omeprazole alone, respectively 


\section{Research trends in British gastroenterology: publication rates in newly appointed NHS consultants over a nine year period}

It has been suggested that medical research within the UK may be in decline. ${ }^{2}$ Possible explanations for this could be the shortened training scheme created by the Calman Specialist Registrar ( $\mathrm{SpR}$ ) post, reduced availability of research funding, or the progressive expansion of the consultant body (as a government imperative to provide a consultant delivered service). ${ }^{1-4}$ Although this may be the perception, there has previously been no published evidence to demonstrate a reduction in research output. In this study, we wished to observe any overall trend in the number of publications and higher degrees that trainees (in gastroenterology) have at the time of their National Health Service (NHS) consultant appointments over a nine year period.

Participants, methods, and results

All consultant appointments and place of training were noted over a fixed period from February 1993 to April 2001 (courtesy of the British Society of Gastroenterology (BSG)). The BSG is considered to have a comprehensive list of its trainees and consultants. ${ }^{4}$ This has been used as a source for the prediction of manpower needs in gastroenterology. ${ }^{4}$ This model has subsequently been applied to other medical subspecialties. ${ }^{4}$ We cross referenced this source with the Medical Directory and BSG members' handbook. We performed a PubMed and Embase search noting the number and type of publications of each consultant. This search included a lag time of up to 19 months post-appointment. This period has previously been described as the mean time from submission to publication. ${ }^{5}$ Higher degrees held by each consultant were also noted.

Over the nine years, 349 appointments were made. We excluded consultant to consultant transfers and appointments to or from academic posts $(n=52)$. Also excluded were trainees who had subsequently left the UK or the medical register, as well as individuals where data were difficult to obtain due to name and centre similarities $(\mathrm{n}=50)$.

Statistical analysis was performed using Microsoft Excel to produce a linear regression line and correlation coefficient $(r)$ to show the trend and strength of any relationship of the median publication rate over the time sampled. The nine years of medians gave 7 degrees of freedom $(\mathrm{df}=7)$. We used $\chi^{2}$ distribution to show any significant difference between the groups.

There was a year by year significant decreasing trend in the median number of publications by SpRs prior to their NHS consultant appointment, from 19 in 1993 to five in 2001 (fig 1).

Specifically assessing first author publications revealed a similar downward trend $(r=0.836 \mathrm{df}=7 ; \quad \mathrm{p}<0.01)$. No statistical differences were observed between university hospital and district general hospital consultants when considering mean publication rates or obtaining a higher degree (data available but not supplied).

\section{Comment}

This is the first study to demonstrate a significant decreasing trend in the number

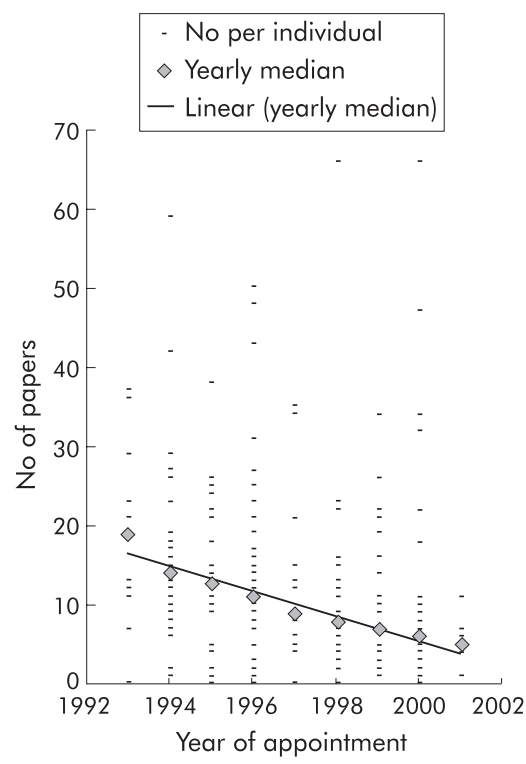

3 Mather HM. Consultant post prospects in medical specialites. J R Coll Physicians Lond 2000;34:289-94.

4 Burnham WR. NTN and all that! Will specialist registrars get a consultant post and will consultants have a registrar? J $R$ Coll Physicians Lond 2000;34:500-1.

5 Sanders DS, Carter MJ, Hurlestone PD, et al. Research outcomes in British gastroenterology: an audit of the subsequent full publications of abstracts presented at the British Society of Gastroenterology. Gut 2001;49:154.

\section{Diagnostic endoscopy: does it help?}

Having questioned the value of therapeutic endoscopy, let me question the value of diagnostic endoscopy, having lived through the days from when it was not available to its current status. Having given the matter considerable thought, ${ }^{1}$ I seriously doubt that it has been of any value. It might even have had an adverse effect on outcome by delaying operative intervention in those who need it and among whom most deaths occur.

If done emergently it is difficult to visualise the bleeding site, especially in those who require surgery and whose rate of blood loss is greatest. Its greatest value may be in excluding the presence of oesophageal bleeding from varices but this is arguably best done on the operating table by the surgeon. In the UK, many centres no longer perform endoscopy emergently preferring to wait until the bleeding has stopped and a better diagnostic evaluation can be made on the daily endoscopy list. This may be good for documentation but is of doubtful benefit in managing patients because of the inevitable delay in surgical intervention in those that need it.

Operative mortality for bleeding ulcers used to be in the order of $15 \%$. I suspect it is very much higher today because surgeons do far less ulcer surgery. This is likely to be especially true if the operations are delegated to registrars in the middle of the night. It might be wise to take a fresh look at the problem.

R G Fiddian-Green year period. It may be that they represent trainees who never published throughout their training. This would suggest even less overall academic activity than we have described.

Our data support the hypothesis that medical research (at least among NHS consultants) is in decline. Similar studies are required to validate this observation within other medical subspecialties (in the UK) and in other countries.

\section{Acknowledgements}

We would wish to thank Diane Mathias (Trainees in Gastroenterology) for her invaluable help in the collection of this data.

A D Hopper, R Atkinson, L Prtak, D S Sanders Gastroenterology and Liver Unit, Royal Hallamshire Hospital, Sheffield, UK

Correspondence to: Dr A D Hopper, Room P39 P Floor, Royal Hallamshire Hospital, Glossop Rd, Sheffield S10 2JF, UK; andydhopper@aol.com

\section{References}

1 Stewart PM. Academic medicine: a faltering engine. BMJ 2002;324:437-8.

2 Mather HM. The research plans of specialis registrars: the RCP SpR questionnaire survey. $J$ R Coll Physicians Lond 2000;34:456-7.

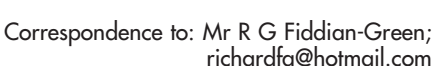

\section{Reference}

1 Fiddian-Green RG, Turcotte JG, eds. Gastrointestinal hemorrhage. New York: Grune and Stratton, 1980.

\section{Prediction of oesophageal varices with platelet count/ spleen diameter ratio or platelets alone}

We read with great interest the article by Giannini et al on platelet count/spleen diameter ratio or platelets alone as predictors of oesophageal varices (Gut 2003;52:1200-5).

As the incidence of chronic liver diseases is growing, we are convinced that the development of non-invasive predictive tools to identify cirrhotic patients with oesophageal varices is of major interest. Several markers have been studied, and among them platelet count is commonly reported to be a good predictor of oesophageal varices. However, in the eight studies already published, ${ }^{1-8}$ their discriminative power was moderate, with 
areas under the receiver operating curve (ROC) of 0.70 or less for platelets alone and for indexes combining platelets with other markers. ${ }^{145}$ Most of these studies included heterogeneous groups of patients, with compensated and decompensated cirrhosis.

In our unit, we performed prospectively platelet count and screening upper oesogastroduodenoscopy on the same day in 41 patients with compensated cirrhosis and confirmed the moderate value of platelet count alone (AUROC $=0.70$ (0.07); Thabut, data not shown). The major drawback of platelet count is that it can depend on factors other than portal hypertension in cirrhotic patients. To avoid this bias, Giannini et al developed an index based on platelet count/ spleen diameter ratio and found far better results than previous studies, with a c index (equivalent to the area under the ROC) of 0.92 for patients with compensated liver cirrhosis. However, we were surprised to see that the use of platelets/spleen diameter ratio did not add significant discrimination to platelet count alone (c index of $0.92 v 0.88$ ) in their population.

On this point, their excellent results could not be explained by the discriminative power of their index but by the excellent diagnostic power of platelet count alone in their series. Several explanations can be raised, and one is the high rate of viral related cirrhosis in their patients where platelet count is less liable to variations compared with, for example, in alcoholic patients. This point is of major concern for the further validation of their index, recommended by the authors themselves, in other populations.

In conclusion, Giannini et al have found a very good index for predicting the presence of oesophageal varices in cirrhotic patients. We believe that the excellent results they obtained were not due to their index but to the surprisingly good performance of platelet count alone in their patients. Considering the results for platelet count as a predictor of oesophageal varices in previously published studies, we fear that the warranted validation studies of this index will show less exciting results.

D Thabut, V Ratziu, J-B Trabut, T Poynard Hepatogastroenterology, Pitié-Salpêtrière Hospital, Paris, Franc

Correspondence to: Dr D Thabut, Hepatogastroenterology, Pitié-Salpêtrière Hospital, 47-83 bd de l'hôpital, Paris 75013, France; dthabut@ libertysurf.fr

\section{References}

1 Chalasani N, Imperiale TF, Ismail A, et al. Predictors of large esophageal varices in patients with cirrhosis. Am J Gastroenterol 1999;94:3285-91.

2 Madhotra R, Mulcahy HE, Willner I, et al. Prediction of esophageal varices in patients with cirrhosis. J Clin Gastroenterol 2002;34:81-5.

$3 \mathrm{Ng} \mathrm{FH}$, Wong SY, Loo CK, et al. Prediction of oesophagogastric varices in patients with liver cirrhosis. J Gastroenterol Hepatol 1999; 14:785-90.

4 Pilette C, Oberti F, Aube C, et al. Non-invasive diagnosis of esophageal varices in chronic liver diseases. J Hepatol 1999:31:867-73.

5 Schepis F, Camma C, Niceforo D, et al. Which patients with cirrhosis should undergo endoscopic screening for esophageal varices detection? Hepatology 2001;33:333-8.

6 Thomopoulos KC, Labropoulou-Karatza C, Mimidis KP, et al. Non-invasive predictors of the presence of large oesophageal varices in patients with cirrhosis. Dig Liver Dis 2003;35:473-8.

7 Zaman A, Hapke R, Flora K, et al. Factors predicting the presence of esophageal or gastric varices in patients with advanced liver disease. Am J Gastroenterol 1999;94:3292-6.

8 Zaman A, Becker T, Lapidus J, et al. Risk factors for the presence of varices in cirrhotic patients without a history of variceal hemorrhage. Arch Intern Med 2001;161:2564-70.

\section{Author's reply}

We thank Thabut et al for their interesting comments on our paper (Gut 2003;52:12005). Indeed, their letter allows us to focus on some aspects of our study that we feel need to be emphasised further.

As a general rule, a surrogate marker for a given variable (that is, presence/absence of oesophageal varices) that already has a definite diagnostic procedure (that is, endoscopy) should fulfil two major criteria. Firstly, it should be the product of a thorough statistical analysis and secondly, but no less importantly, it has to be biologically plausible.

From a statistical point of view, as Thabut et al correctly point out, both platelet coun and the platelet count/spleen diameter ratio showed excellent diagnostic accuracy for the non-invasive diagnosis of the presence absence of oesophageal varices. However we do not agree with their assumption that the use of the platelet count/spleen diameter ratio did not add significant discrimination to the use of platelet count alone. In fact, the accuracy of the platelet count/spleen diameter ratio for the diagnosis of oesophageal varices was not only better than that of platelet count alone but was also significantly so. Briefly, in the cohort of 145 patients with compensated cirrhosis, which is the group that most likely benefits from screening, the difference between the AUC-ROC of the platelet count/spleen diameter ratio and platelet count was $0.041(0.013-0.070)$, with $\mathrm{p}=0.005$ in favour of the platelet count spleen diameter ratio. Moreover, in the whole cohort of 266 patients, the platelet count/ spleen diameter ratio had a c index of 0.902 (95\% confidence interval 0.860-0.935) while platelet count alone had a c index of 0.839 (0.790-0.881), with a difference between AUC-ROC of $0.063 \quad(0.038-0.088)$ $(\mathrm{p}=0.001)$. Furthermore, the platelet count/ spleen diameter ratio was the only parameter significantly associated with the presence/ absence of oesophageal varices in a multivariate analysis that also included platelet count. Lastly, as recently highlighted, the negative predictive power of a non-invasive parameter used to predict the absence/presence of oesophageal varices is a fundamental clinical concern. ${ }^{1}$ In fact, for such a tool to be adopted in clinical practice it has to achieve a negative predictive value of $100 \%$ although maintaining an acceptable positive predictive value. This would preserve the safety of the parameter (that is, virtual absence of missing a diagnosis) and keep a satisfactory costefficacy profile. In practice, in our study the use of the platelet count/spleen diameter ratio fulfilled these criteria while platelet count alone did not.

Biological plausibility is a not a secondary concern for the clinician. As we emphasised in our paper and recently demonstrated, ${ }^{2}$ and as Thabut et al also pointed out, the presence of thrombocytopenia in patients with liver cirrhosis is likely a multifactorial event. Therefore, the use of platelet count to diagnose a feature that depends on portal hypertension alone may lead to an increase in false positive results, thus decreasing the accuracy as well as the cost-efficacy of the diagnostic procedure. As highlighted in our paper, the use of the platelet count/spleen diameter ratio could bypass this inconvenience by "normalising" platelet count to the platelet count decrease effectively dependent on hypersplenism.

Lastly, some methodological issue should be taken into account when the two items of the ratio are singularly evaluated. On the one hand, the spleen diameter measurement should be performed by a skilled operator, and its results should have excellent accuracy and reproducibility. On the other hand, we have shown that the consistency of the ratio is maintained, even considering the expected mild fluctuations in platelet count commonly seen in cirrhotic patients during a limited period of time.

All in all, we did not presume to propose a diagnostic "magic bullet", as is more and more commonly being proposed in clinical hepatology. We are well aware that the results we obtained have to be validated in independent series and/or in cohorts with different aetiologies of liver disease before being widely accepted, ${ }^{4}$ and in our paper we clearly stated the limitations of our study. However, our patient population is that which we commonly encounter in everyday clinical practice, and it is not very different from that seen in other parts of our country (that is, viral cirrhosis in approximately $70 \%$ of patients). ${ }^{5}$ Moreover, if we look outside our borders, we see that our population is not very different from others, viral aetiology of liver disease being the leading cause of liver transplantation in Europe during the period January 1998 to December 2001 (22 924 cirrhotic patients). ${ }^{6}$ Nevertheless, if we examine our data we see that the use of the platelet count/spleen diameter ratio performs equally good in the limited subset of patients with alcoholic cirrhosis $(n=53$, platelet count spleen diameter ratio $\mathrm{c}$ index $=0.958$, platelet count $\mathrm{c}$ index $=0.740$, difference between AUC-ROC $=0.218 ; \quad \mathrm{p}=0.001$ ), although we feel that focusing on a specific subgroup of patients that does not reflect the true prevalence of the disease in the population would introduce bias.

In conclusion, we have proposed a new evaluation tool and called for validation of our method, being conscious that only differences in opinion that arise from results obtained in well conducted studies contribute to scientific progress, and most importantly that "life is short, and art long; the crisis fleeting; experience perilous, and decision difficult. The physician must not only be prepared to do what is right himself, but also to make the patient, the attendants, and externals cooperate"

E G Giannini, F Botta, R Testa Gastroenterology Unit, Department of Internal Medicine, University of Genoa, Italy

Correspondence to: Dr E G Giannini, Gastroenterology Unit, Department of Internal Medicine, University of Genoa, Viale Bendetto XV, No 6 Genoa, Italy; egiannini@unige.it

\section{References}

1 de Franchis R. Evaluation and follow-up of patients with cirrhosis and oesophageal varices. J Hepatol 2003;38:361-3. 
2 Giannini E, Botta F, Borro P, et al. Relationship between thrombopoietin serum levels and liver function in patients with chronic liver disease related to hepatitis $C$ virus infection. Am J Gastroenterol 2003;98:2516-20.

3 Peck-Radosavljevic M. Thrombocytopenia in liver disease. Can J Gastroenterol 2000;14(suppl D):60-6D.

4 Laupacis A, Sekar N, Stiell IG. Clinical prediction rules. A review and suggested modifications of methodological standards. JAMA 1997:277:488-94.

5 De Bac C, Clementi C, Duca F, et al. Liver cirrhosis: epidemiological aspects in Italy. Res Virol 1997; 148:139-42.

6 European Liver Transplant Registry. Primary indications of liver transplantation in cirrhosis in Europe. http://www.eltr.org/publi/ results.php3?id_rubrique $=48$. Accessed 26 November, 2003

7 Hippocrates. Aphorisms, I.

\section{Computed tomography colonography: colon examination or Pandora's box}

We read with interest the article by Ginnerup Pedersen et al (Gut 2003;52:1744-7) investigating the frequency and diagnostic consequences of extracolonic findings at multidetector computed tomography (MDCT) colonography.

The authors noted extracolonic findings in $65 \%$ of cases, with the need for further workup in $12 \%$ and surgery in $3 \%$. The authors concluded that the high prevalence of extracolonic findings may make MDCT colonography a problematic colorectal cancer screening tool for both ethical and economic reasons

We would like to comment on the question raised by Ginnerup Pedersen et al-namely, whether MDCT colonography should be regarded as a colon examination or a sort of "Pandora's box" (if used for abdominal screening)

Notably, a recent article has emphasised that one of the major potential advantages of MDCT colonography in comparison with all other existing colorectal diagnostic tests is its ability to detect disease outside the colon. ${ }^{1}$ Indeed, the possibility that extracolonic disease can be readily identified at CT colonography has been extensively investigated in the literature, ${ }^{2-4}$ with results similar to the ones presented by Ginnerup Pedersen et al .

However, there is evidence that although the vast majority of extracolonic findings are of little clinical importance, such findings may lead to unnecessary further workup, with obvious economic, medicolegal, and psychological implications. ${ }^{3}$ Therefore, the possibility of "looking" outside the colonic lumen can be seen as a "double edged sword" or "Pandora's box".

In this regard, we feel that three important issues need to be emphasised. Firstly, CT colonography is usually performed with a low dose technique which exploits the high contrast that exists at the colonic mucosaair interface. ${ }^{45}$ Such a low dose technique is adequate for evaluation of colorectal lesions but substantially limits the assessment of solid organs. ${ }^{45}$ In addition, there is a recent trend to reduce even further the radiation dose of CT colonography. ${ }^{5}$ For instance, the radiation dose in millisieverts $(\mathrm{mSv})$ is $10 \mathrm{mSv}$ for standard abdominal CT, ${ }^{6} 6 \mathrm{mSv}$ in the study of Ginnerup Pedersen et al, and 1.8-2.4 mSv in our hospital. ${ }^{5}$ Clearly, the lower the radiation dose, the lower the extracolonic diagnostic ability.
Secondly, in order to reduce the cost and increase the safety of the examination, CT colonography is usually performed without administration of intravenous contrast material. ${ }^{3}$ Clearly, this reduces even further the ability of CT colonography to detect and characterise extracolonic findings.

Thirdly, and perhaps most importantly, CT colonography has recently been demonstrated to be suitable for colorectal cancer screening purposes. ${ }^{7}$ However, there is no agreement regarding the use of standard abdominal CT for general abdominal screening. ${ }^{89}$ At present, abdominal CT screening is not supported by scientific evidence, ${ }^{9}$ United States Food and Drug Administration approval, ${ }^{6}$ or the American College of Radiology recommendation. ${ }^{10}$

It is clear that due to the use of a low dose technique and lack of intravenous contrast administration, CT colonography has even lower diagnostic ability than standard abdominal CT for assessment of disease outside the colon. Thus it is of paramount importance that radiologists, referring physicians, and patients are aware that CT colonography is not designed for the detec tion of extracolonic findings and should therefore be considered primarily as a colon examination. Due to the high prevalence of extracolonic abnormalities, radiologists should be alert to appropriate additional workup for triage patients to avoid opening a potential "Pandora's box".

R lannaccone, A Laghi, C Catalano, F Mangiapane, D Marin, R Passariello Department of Radiological Sciences, University of Rome-La Sapienza, Rome, Italy

Correspondence to: Dr R lannaccone, Via A Graf, 40 Rome, Italy; r_iannaccone@yahoo.it

\section{References}

1 Rex DK. Barium studies/virtual colonoscopy: the gastroenterologist's perspective. Gastrointest Endosc 2002;55(suppl 7):S33-6.

2 Hara AK, Johnson CD, MacCarty RL, et al. Incidental extracolonic findings at CT colonography. Radiology 2000;215:353-7.

3 Edwards JT, Wood CJ, Mendelson RM, et a Extracolonic findings at virtual colonoscopy: implications for screening programs. Am J Gastroenterol 2001;96:3009-12.

4 Gluecker TM, Johnson CD, Wilson LA, et al. Extracolonic findings at CT colonography: evaluation of prevalence and cost in a screening population. Gastroenterology 2003; 124:911-16.

5 lannaccone R, Laghi A, Catalano C, et al. Detection of colorectal lesions: lower-dose multidetector row helical CT colonography compared with conventional colonoscopy. Radiology 2003;229:775-81.

6 United States Food and Drug Administration web site. Whole body scanning using computed tomography (CT). Available at, www.fda.gov. Accessed 1 December, 2003.

7 Pickhardt PJ, Choi JR, Hwang I, et al. Computed tomographic virtual colonoscopy to screen for colorectal neoplasia in asymptomatic adults. N Engl J Med 2003;349:2191-200

8 Brant-Zawadzki M. CT screening: why I do it. Am J Roentgenol 2002;179:319-26.

9 Baker SR. Abdominal CT screening: inflated promises, serious concerns. Am J Roentgenol 2003; 180:27-30.

10 American College of Radiology Web site Available at: www.acr.org/publications, Accessed 1 November 2002 laccessible only to ACR members).

\section{Patients' understanding of colonoscopy risk is suboptimal}

We read with interest the British Society of Gastroenterology (BSG) lead audit by Bowles et al (Gut 53:277-83) into colonoscopy practice within the UK. As part of the audit the authors questioned 1200 patients on their experience of the procedure. Of the respondents, only $81.5 \%$ received written information, with only $54.9 \%$ recalling information on possible adverse events such as bleeding and perforation. The poor recollection of potential problems is perhaps to be expected if the audit questionnaire was sent to patients sometime after the procedure.

In common with many endoscopy units, we send out an information leaflet with the patient's appointment details. This explains the preparation required, what to expect on the day, and any potential complications, with advice as to what to do should these complications arise. As there are concerns regarding patients' understanding of potential complications related to endoscopy, we designed a short questionnaire to determine how much information patients were able to recall from the information leaflet sent to them prior to colonoscopy. This consisted of four multichoice questions with five possible answers, of which only one was correct. The correct answers were all in the information leaflet. Patients were requested to complete the questionnaire just prior to discharge, at least one hour after procedure completion, thus minimising the effects of sedation. The questions related to: the risk of perforation; the degree of rectal bleeding that required medical assistance; what to do should a problem arise out of office hours; and the correct means of getting home after receiving sedation.

Thirty three patients completed the colonoscopy questionnaire and of these only 37\% answered all four questions correctly. Only $52 \%$ of patients remembered correctly the perforation rate from diagnostic colonoscopy, which was stated as 1 in a 1000 in our information leaflet. Worryingly, 12 patients $(36 \%)$ thought that perforation rates were 10-100-fold lower than stated in the information leaflet.

Our study demonstrates that patients fail to fully appreciate the risks of colonoscopy despite the distribution of detailed written information prior to the procedure. This could have medicolegal implications should complications arise and reinforces the need for improved methods of informing patients.

R J Makins, D S Rampton Barts and The London Hospital NHS Trust, London, UK A B Ballinger Homerton University Hospital NHS Trust, Homerton Row, London, UK

Correspondence to: Dr R Makins, Barts and The London Hospital NHS Trust, DDRC, Turner St, London El 2AD, UK; r.j.makins@qmul.ac.uk

\section{CORRECTION}

In the paper by Hawkey et al (Gut 2003;52 $820-826$ ), the key relating to figure 2 was incorrectly labelled. The key currently shows "Placebo/ Rofecoxib 500mg/ Naproxen 500mg." The drug dosage should have read "Placebo/ Rofecoxib 50mg/ Naproxen 500mg." 


\section{NOTICES}

British Society of Gastroenterology Paul Brown Travel Fellowships

The Paul Brown Travel Fellowships are awarded by the Endoscopy Committee of the BSG. They are intended to assist trainee gastroenterologists and established consultants in visits to units outside the United Kingdom for specialist experience and training in endoscopy.

Specialist registrars who have not achieved their CCST are expected to have the approval of their Postgraduate Dean and their Regional Training Director when they apply for a Travel Fellowship. Applicants are expected to provide confirmation that they have been accepted for training in the unit that they wish to visit.

Successful applicants will be expected to provide a brief written report to the Endoscopy Committee of the outcome of their visit.

Application forms are available from the British Society of Gastroenterology Office, 3 St Andrew's Place, London NWl 4LB. Email: bsg@mailbox.ulcc.ac.uk

\section{European Postgraduate Gastro-} surgical School (EPGS) Courses 2004

The EPGS at the Academic Medical Center of the University of Amsterdam will be holding the following courses during the year: 'Endosonography live in Amsterdam' will be held on 2, 3 \& 4 June 2004, and 'Update in Coloproctology' will be held on 28 \& 29 October 2004. For further information, please contact: J Goedkoop (tel: (31) 566 3926; fax: (33) 267 5594; e-mail: j.goedkoop@amc.uva.nl; website: www.epgs.nl).

\section{$8^{\text {th }}$ Southeast European Symposium of Paediatric Surgery}

The $8^{\text {th }}$ Southeast European Symposium of Paediatric Surgery will focus upon 'Infectious Problems in Paediatric Surgery.' The event will be held between 24-25 September 2004, at the University of Graz, Austria For further information, please contact: Professor M E Höllwarth Department of Paediatric Surgery, Medical University of Graz, Austria, Auenbruggerplatz 34, 8036 Graz; tel: + 43316385 3762; fax: tel: + 43 3163853775 ; e-mail: kinderchirurgie@ uni-graz.at.

\section{$12^{\text {th }}$ European Symposium on Neurogastroenterology and Motility}

The $12^{\text {th }}$ European Symposium on Neurogastroenterology and Motility will be taking place at Robinson College, Cambridge, UK.
The symposium will be taking place on 15 18 September 2004

On Wednesday 15 September, there will be a postgraduate teaching day. This will cover established and evolving assessments of oesophageal, gastric and intestinal function, visceral sensitivity and brain responses. Basic science techniques including electrophysiology, imaging of gut movements and neural activation will be covered in the afternoon. Finally there will be a session on GI pharmacology covering cytokines, capsaicin and tachykinins.

On Thursday 16 September through to Saturday 18 September midday, the main meeting will be held. This will include symposia, oral free papers and poster rounds. The symposia will be designed to move from basic science to clinical practice and will include sessions on stress and the gut, appetite and obesity, serotonin and inflammation, and inflammation and GI motility. There will also be state of the art lectures and prize presentations.

For registration and further information please see the website www.neurogastro.org, and follow links for '12th European Symposium on Neurogastroenterology and Motility.' Please contact the conference organizers at: Confrex, PO Box 21, Rottingdean, East Sussex, BN2 8WZ (tel: $+44(0) 1273$ 302200; fax: +44(0)1273 302334; e-mail: confrex@easynet.co.uk). 


\section{PostScript}

\section{LETTERS}

If you have a burning desire to respond to a paper published in the Gut, why not make use of our "rapid response" option?

Log on to our website (www.gutjinl.com), find the paper that interests you, and send your response via email by clicking on the "eletters" option in the box at the top right hand corner.

Providing it isn't libellous or obscene, it will be posted within seven days. You can retrieve it by clicking on "read eletters" on our homepage.

The editors will decide as before whether to also publish it in a future paper issue.

\section{High magnification chromoscopic colonoscopy as a screening tool in acromegaly}

We read with great interest the paper by Jenkins et al (Gut 2002;51:Vl3-14) regarding screening guidelines for colorectal cancer (CRC) and polyps in patients with acromegaly and the subsequent discussion by Renehan addressing screening inconsistencies compared with other high risk groups. ${ }^{12}$

The optimal colorectal screening modality and frequency in this group however requires clarification. Colonoscopy in this patient group is technically demanding and often complicated by inadequate bowel preparation. ${ }^{3}$ However, despite current controversies regarding true CRC risk categorisation in acromegaly, previous data from the largest published series showed a trend for adenoma and carcinoma formation in the right hemi colon. ${ }^{4}$ This is an important observation for many reasons.

Flat adenomas and carcinomas can be difficult to detect by conventional colonoscopy alone, often presenting as subtle mucosal erythema, mucosal pallor, fold convergence, interruption of innominate grooves, air induced deformation, or loss of vascular net pattern. ${ }^{5}$ The neoplastic risk for this morphologically distinct group has additionally been shown by many authors to be higher when compared with exophytic polypoid lesions and exhibit a propensity for the right colon. ${ }^{6-9}$ De novo neoplastic lesions and "minute" colorectal cancers are also associated with an increased risk of lymph node metastasis due to early invasion of the submucosal layer..$^{10}$ Tada et al found extensive submucosal invasion in a cohort of flat colorectal neoplasms, ${ }^{11}$ with Shimoda's series corroborating these data with submucosal invasion demonstrable in $69 \%$ of flat carcinomas compared with only $35 \%$ of sessile and broad based polypoid carcinomas. ${ }^{12}$

Morphologically flat and depressed lesions are also known to occur in chronic ulcerative colitis $^{13}$ where the need for CRC screening with total colonoscopy and now adjunctive chromoscopy is adopted by many centres. Failure to detect such lesions may in part account for those cases of CRC which occurred in Winawer's study, despite clearance of all exophytic polyps, and thus stresses the requirement for accurate diagnosis and definitive treatment of these high risk lesions. ${ }^{14}$

Given the lack of standardised and uniform reporting regarding the morphology of colorectal lesions in many of the existing prevalence studies of adenomas and CRC in acromegaly however, at present we can only hypothesis that the high incidence of right hemi colonic neoplasia may be an indicator of an alternative morphologically distinct lesion such as the flat adenoma and carcinoma with a trend towards a de novo pathogenic sequence.

In our prospective study, 38 patients with acromegaly underwent total colonoscopy by a single endoscopist using the Olympus C240Z magnifying colonoscope. Preparation was with 4 litres of Kleanprep 24 hours prior to the procedure. Pancolonic chromoscopy using $0.5 \%$ indigo carmine sprayed onto the colonic mucosa using an Olympus diffusion catheter (CS12890) was applied. Identified lesions were morphologically grouped according to the Japanese Research Society Classification (JRSC). ${ }^{15} 16$ A flat lesion was defined as mucosal change with a flat or rounded surface combined with a height of less than half the diameter of the lesion. ${ }^{17}$ High magnification views of all suspected lesions were then obtained and reported according to the modified Kudo criteria. ${ }^{18}$ Tissue sampling was performed with cold biopsy or endoscopic mucosal resection following exclusion of a Kudo type $\mathrm{V}(\mathrm{n}) / \mathrm{III}$ invasive crypt pattern which suggests deep submucosal invasion. Mean intubation and extubation times were recorded. Neoplastic change was classified according to the Vienna criteria. ${ }^{19}$
Caecal intubation was achieved in $37 / 38$ (97\%) patients with 36/38 (94\%) receiving confirmatory terminal ileal biopsies. Males represented 14/37 (37\% of the cohort, mean age 64 years (range 40-75)). The mean duration of intubation to the caecum was 16.5 minutes (range 3-31) and extubation (excluding interventional procedures) was 35 minutes (range 20-55). There were no complications.

A total of 28 lesions were identified in 15 patients. Twenty two hyperplastic lesions were identified $(79 \%)$ of which $17(77 \%)$ were flat (JRSC II). Twenty (91\%) were located in the left colon and rectum. Of the five adenomas identified, four $(80 \%)$ were present in the right colon with $4 / 5(80 \%)$ being of JRSC II morphology. A single adenoma with high grade dysplasia was present in the right colon and was flat with a small area of central depression. No invasive carcinomas were diagnosed. Results are summarised in table 1.

Although the numbers entering this study are small, our results show a clear prevalence for JRSC class II lesions in this select patient group. Although only one adenoma with high grade dysplasia was detected, it was small $(5 \mathrm{~mm})$ and was not identified prior to chromoscopic and magnification enhancement, and therefore carries major clinical connotations.

We suggest that further large prospective studies are required to establish the true prevalence of flat and depressed colorectal lesions in acromegaly so that the optimal screening modality and frequency can finally be established. Furthermore, colonoscopists require training in chromoscopic techniques if a higher endoscopically "treatable" lesional frequency is to be detected at a screening level, so as to avoid the high apparent incidence of interval neoplasms.

D P Hurlstone, S S Cross, A J Lobo, D S Sanders Halamshire Hospital, Sheffield, UK

Correspondence to: Dr D P Hurlstone, 17 Alexandra Gardens, Lyndhurst Rd, Nether Edge, Sheffield S11 9DQ, UK; p.hurlstone@shef.ac.uk

\section{References}

1 Renehan AG, O'Dwyer ST, Shalet SM. Colorectal neoplasia in acromegaly: the reported increased prevalence is overestimated. Gut 2000:46:440.

2 Renehan AG, O'Dwyer ST, Shalet SM. Guidelines for colonoscopic screening in acromegaly are inconsistent with those for other high risk groups. Gut 2003:52:1071-2

Table 1 Lesion demographics

\begin{tabular}{|c|c|c|c|c|c|c|c|}
\hline \multirow[b]{2}{*}{ Histology } & \multirow[b]{2}{*}{ n } & \multicolumn{2}{|c|}{ Morphology (JRSC) } & \multirow[b]{2}{*}{ Dominant crypt pattern } & \multirow[b]{2}{*}{ Mean size $(\mathrm{mm})$} & \multicolumn{2}{|c|}{ Anatomical location } \\
\hline & & 1 & II & & & Rt colon & Lt colon/rectum \\
\hline Hyperplastic & 22 & 5 & 17 & $1 / I I$ & 6 & 2 & 20 \\
\hline Adenoma LGD & 5 & 1 & 4 & IIIL & 6.5 & 4 & 1 \\
\hline Adenoma HGD & 1 & 0 & 1 & $V(a)$ & 5 & 1 & 0 \\
\hline $\begin{array}{l}\text { Invasive neoplasia } \\
\text { (T2 or beyond) }\end{array}$ & 0 & 0 & 0 & Nill & & 0 & 0 \\
\hline
\end{tabular}

LGD, low grade dysplasia; HGD, high grade dysplasia. 
3 Veysey MJ, Mills TD, Thomas LA, et al. Prolonged large bowel transit increases serum deoxycholic acid: a risk factor for octreotide induced gallstones. Gut 1999:44:675-81.

4 Jenkins PJ, Fairclough PD, Richards T, et al. Acromegaly, colonic polyps and carcinoma. Clin Endocrinol 1997; 47: 17-22.

5 Hurlstone DP, Fujii T, Lobo AJ. Early detection of colorectal cancer using high-magnification chromoscopic colonoscopy. Br J Surg 2002;89:272-82

6 Rembacken BJ, Fujii T, Cairns A, et al. Flat and depressed colonic neoplasms: a prospective study of 1000 colonoscopies in the UK. Lancet 2000;355:1211-14

7 Tsuda S, Veress B, Toth E, et al. Flat and depressed colorectal tumours in a southern Swedish population: a prospective chromoendoscopic and histopathological study. Gut 2002;51:550-5.

8 Saitoh Y, Waxman I, West AB, et al. Prevalence and distinctive biologic features of flat colorectal adenomas in a North American population. Gastroenterology 2001;120:1657-65.

9 Adachi M, Okinaga K, Muto T. Flat adenoma of the large bowel: re-evaluation with special reference to central depression. Dis Colon Rectum 2000;43:782-7.

10 Kudo S, Tamura S, Hirota S, et al. The problem of de novo colorectal carcinoma. Eur $J$ Cancer 1995:31A: 1118-20.

11 Tada S, Yao T, lida M, et al. A clinicopathologic study of small flat colorectal carcinoma. Cancer 1994; 74:2430-5

12 Shimoda T, Ikegami M, Fujisaki J, et al. Early colorectal carcinoma with special reference to its development de novo. Cancer 1989;64:1138-46.

13 Kiesslich R, Fritsch J, Holtmann M, et al. Methylene blue-ailed chromoendoscopy for the detection of intraepitheial neoplasia and colon cancer in ulcerative colitis. Gastroenterology 2003;124:880-8

14 Winawer SJ, Zauber AG, Ho MN, et al. Prevention of colorectal cancer by colonoscopic polypectomy. The National Polyp Study Workgroup. N Engl J Med 1993;329:1977-81.

15 General rules for clinical and pathological studies on cancer of the colon, rectum and anus. Part I. Clinical classification. Japanese Research Society for Cancer of the Colon and Rectum. Jpn J Surg 1983;13:557-73

16 General rules for clinical and pathological studies on cancer of the colon, rectum and anus. Part II. Histopathological classification. Japanese Research Society for Cancer of the Colon and Rectum. Jpn J Surg 1983;13:574-98.

17 Kudo S, Kashida H, Tamura T, et al. Colonoscopic diagnosis and management of nonpolypoid early colorectal cancer. World I Surg 2000;24:1081-90.

18 Kudo S, Rubio CA, Teixeira CR, et al. Pit pattern in colorectal neoplasia: endoscopic magnifying view. Endoscopy 2001;33:367-73.

19 Schlemper RJ, Riddell RH, Kato Y, et al. The Vienna classification of gastrointestinal neoplasia. Gut 2000;47:251-5.

\section{Fetal "cardiac mucosa" is not adult cardiac mucosa}

De Hertogh et al's autopsy study of the fetal gastro-oesophageal region provides valuable insight into the development of foregut epithelium in the 13-24 week gestational period (Gut 2003;52:791-6). Coincidentally, two other studies appeared on the same subject in April 2003. ${ }^{12}$ These studies were stimulated by our hypothesis that cardiac mucosa does not exist as a normal structure in humans. ${ }^{34}$

Three columnar epithelial types are reported between squamous epithelium and parietal cell containing gastric mucosa in De Hertogh's study (Gut 2003:52:791-6). These are called "primitive oesophageal mucosa", "primitive stomach mucosa", and "cardiac mucosa". Careful anatomical correlation place all of these mucosae in the oesophagus, proximal to the gastro-oesophageal junction "Primitive oesophageal mucosa" is a ciliated epithelium that disappears at 24 weeks. "Proximal stomach mucosa" is a layer of flat columnar cells containing depressions that correspond to early gland pits distally. "Cardiac mucosa" is composed of foveolar and surface epithelium overlying glandular structures containing no parietal cells. The description of "cardiac mucosa" and figs 2 and 4 show a very thin columnar epithelium composed of uniform mucous cells with foveolar pits and rudimentary sac-like structures devoid of any inflammation. Derdoy et al's "cardiac mucosa" ${ }^{2}$ and Park et al's "transitional zone"1 are identical in appearance. I have never seen this fetal epithelium in any adult patient. The fact that these authors call it "cardiac mucosa" does not make it identical to the more conventional cardiac mucosa seen in adults. The only similarity is that it is a glandular mucosa composed of mucous cells only. It is much thinner than adult cardiac mucosa, it has no inflammation, and its glands are much less developed if present at all.

I would like to propose an alternate explanation for the changes seen in all three papers that I believe provides a better explanation of the data in the papers. The early fetal oesophagus is lined by primitive undifferentiated ciliated columnar epithelium. It begins differentiating into squamous epithelium proximally and gastric mucosa distally. Gastric differentiation is marked by the appearance of true glands containing parietal cells. In the second trimester, the oesophageal squamous epithelium is separated from parietal cell containing gastric mucosa by a columnar epithelium composed of foregut columnar stem cells forming a flat surface and a foveolar pit. This is uncommitted fetal columnar epithelium. This continues to develop into either squamous epithelium proximally or parietal cell containing gastric mucosa distally, so that its overall length decreases as fetal age increases (as shown in De Hortogh et al and Derdoy et al's studies $^{2}$ ). With completion of the development of the lower oesophageal sphincter in early infant life, the physiological gastrooesophageal junction is defined and the uncommitted columnar foregut epithelium completes its development into squamous in the oesophagus and gastric mucosa with parietal cells distal to the lower oesophageal sphincter. The uncommitted foregut columnar epithelium disappears. The only normal mucosae seen after development is complete are squamous and gastric with parietal cells. This is proven by illustrations that show children with a direct transition of squamous epithelium to gastric mucosa with parietal cells (Chandrasoma and colleagues ${ }^{4}$ and fig $2 \mathrm{~A}$ of Park and colleagues ${ }^{1}$ ). The absence of cardiac mucosa in these illustrations is proof that cardiac mucosa is not universally present in children. Adult-type cardiac mucosa is also absent universally in fetuses. The only reason why De Hertogh et al reach the conclusion that it is universally present in fetal life is that they erroneously apply the term "cardiac mucosa" to the uncommitted fetal columnar epithelium that is universally present in fetal life.

P T Chandrasoma

Professor of Pathology, Keck School of Medicine University of Southern California, Los Angeles, USA ptchandr@usc.edu

\section{References}

1 Park YS, Park HJ, Kang GH, et al. Histology of the gastroesophageal junction in fetal and pediatric autopsy. Arch Pathol Lab Med 2003;127:451-5.

2 Derdoy JJ, Bergwerk A, Cohen H, et al. The gastric cardia: To be or not to be? Am J Surg Pathol 2003;27:499-504.

3 Chandrasoma P. Pathophysiology of Barrett's esophagus. Semin Thorac Cardiovasc Surg 1997:9:270-8.

4 Chandrasoma P, Der R, Ma Y, et al. Histology of the gastroeeosphageal junction - an autopsy study. Am J Surg Pathol 2000;24:402-9.

\section{Author's reply}

We would like to thank Dr Chandrasoma for his attentive reading and kind comments on our work published in Gut. He has also provided the readers with an admirable synthesis of the most recent research on the development of the different mucosal types in the gastro-oesophageal junction region. By means of this letter, we want to reflect on some of his comments.

The quintessence of Dr Chandrasoma's vision on cardiac mucosa $(\mathrm{CM})$ is that it is not a normal structure but develops through metaplasia in the context of gastro-oesophageal reflux disease. The presence of a small length of CM in many "normal" adults could be the result of asymptomatic low level reflux. According to his view the "nonciliated non-glandular late fetal foregut epithelium" (which we call CM in our study) will develop into either oesophageal squamous epithelium or gastric mucosa with parietal cell containing glands. The necessary corollary of his theory is that there can be no such thing as a normal CM. He also puts forward the notion that the presence of $\mathrm{CM}$ in some infants might be due to deviant differentiation of the uncommitted epithelium in the context of reflux or other trauma such as nasogastric intubation. Even if this hypothesis is correct, we think that other possibilities should be considered. One possible situation could be the persistence of the uncommitted epithelium with development of a sort of heterotopic CM (analogous to the heterotopic fundic-type mucosa described in the upper third of the oesophagus). Clearly, much more research is needed.

Obviously, our work is not completely representative of the development of the gastro-oesophageal junction region throughout gestation. Notably, we need extra specimens from third trimester fetuses. At this moment we are gathering this material for future research. As Dr Chandrasoma himself says, the most important reason for the divergent conclusions of his work and ours are the terminology and interpretation of the data. What we call CM is, in $\mathrm{Dr}$ Chandrasoma's opinion, an uncommitted epithelium devoid of glands. He specifically warns against applying the designation "gland" to the tangentially cut tortuous ends of the foveolar pits (our fig 2 and fig 4). We believe glands are present in these illustrations. We formed this conclusion both on a purely morphological basis (the gland cells are cuboidal to triangular and contain a centrally located round nucleus, as opposed to the tall columnar foveolar and pit cells with basically located nuclei) and after histochemical evaluation (the foveolar and pit cells contain a large amount of mostly neutral mucins, whereas the gland cells for a long time contain only a small amount of mostly acidic mucins). We used the term CM 
for this zone interposed between squamous and fundic mucosa because of its morphological analogy with adult CM (whether normal or abnormal). Its principal characteristic is the presence of mucus producing glands devoid of parietal cells. We stated that $\mathrm{CM}$ develops during gestation and is present at birth. We do not know what happens with this CM in infants and children. We cannot comment on the identity of adult CM: has it always been there or did it develop through metaplasia? To prove or disprove Dr Chandrasoma's theory, evidently much further research has to be done.

G De Hertogh, P Van Eyken, K Geboes Dienst Pathologische Ontleedkunde, UZ Leuven, Leuven, Belgium

Correspondence to: Dr G De Hertogh, UZ St-Rafaë Minderbroedersstraat 12, Leuven 3000, Belgium gert.dehertogh@uz.kuleuven.ac.be

\section{Helicobacter pylori infection in Africa and Europe: enigma of host genetics}

Helicobacter pylori infection is one of the most common bacterial infections. The prevalence varies from $25-50 \%$ in developed countries to $70-90 \%$ in the third world. ${ }^{1}$ Despite improved treatment modalities, $H$ pylori related gastrointestinal pathology, in common with gastritis, peptic ulcers and consecutive bleeding events, gastric MALT lymphoma, or carcinoma, remains a major burden on Western health systems. In the USA, approximately four million people have active peptic ulcers and about 350000 new cases are diagnosed each year. Four times as many duodenal ulcers as gastric ulcers are diagnosed Epidemiological evidence suggests that both infection with $H$ pylori and the consecutive development of clinically relevant pathology are influenced by genetic predisposition as only a fraction of exposed individuals develop infection and likewise a fraction of infected individuals develop ulcers or even gastric cancer. $^{3}$

Thye et al used $H$ pylori reactive serum immunoglobulin $\mathrm{G}$ as a marker of $H$ pylori infection in Senegalese siblings and provided for the first time concrete statistical evidence for a genetic predisposition to $H$ pylori infection. The authors reported an association between IFNGRI polymorphisms and high antibody concentrations. ${ }^{4}$ Inclusion of the three variants $(\mathrm{H} 318 \mathrm{P}, \mathrm{L} 450 \mathrm{P},-56 \mathrm{~T} / \mathrm{C})$ in

Table 1 Haplotype analysis of infection status and clinical manifestation of Helicobacter pylori infection

\begin{tabular}{lcc}
\hline Comparison groups & n (groups) & p Value \\
\hline Infection status (normal controls versus all H pylori positive patients) & $\begin{aligned} 311 \text { v 344 } \\
66 \text { v 166 }\end{aligned}$ & 0.39 \\
$\begin{array}{l}\text { Moderate versus mild pathology in H pylori infected patients } \\
\text { (gastric/duodenal erosions versus no pathology or gastritis/duodenitis) }\end{array}$ & & \\
$\begin{array}{l}\text { Severe versus mild pathology in H pylori infected patients } \\
\text { (gastric/duodenal ulcers versus no pathology or gastritis/duodenitis) }\end{array}$ & 112 v 166 & 0.61 \\
\hline
\end{tabular}

The table shows the comparative frequencies of the IFNGRI haplotype described above. Susceptibility to $H$ pylori infection was tested by comparison of all $H$ pylori positive patients ( $n$ : all subgroups: $66+112+166=344$ ) against normal controls (top row). Genetic predisposition for complications of $H$ pylori infection was tested by comparison of patients with moderate pathology (gastric or duodenal erosions, $n=66$ ) and severe pathology (gastric or duodenal ulcers $n=112$ ) against patients with mild or no pathology grouped together (no pathology, gastritis, or duodenitis, $n=166$ ) Significance was assessed by a $\chi^{2}$ test of the global likelihood ratio of the case control haplotype estimations. the linkage analysis increased the LOD score variants, H318P and L450P, were not found

Immediately, the question arises of 1 (IFNGRl) locus is related to at the IFNGRl locus (rs608914 rs11914) in $344 \mathrm{H}$ pylori infected individuals gastrointestinal endoscopy northern Germany and 311 healthy histology. Patients were grouped according to from mild inflammation such as "Asplied Biosystems "An Demand" protocols. Because both polymorphisms were (rs 11914: synonymous T/G exchange in frequency in blood donors $31.3 \%$ ) a haplotype case control analysis was performed using to $^{5}$ to assess the association of the markers exhibited a low degree of linkage disequilibrium $(\mathrm{LD})\left(\mathrm{D}^{\prime}=0.174\right)$ yielding a (frequencies in normal controls: TC significant association with infection status

We conclude that INFGRl is unlikely to be involved in the aetiology of $H$ pylori infection or the development of clinical sequelae in eaucasians. This may be due to

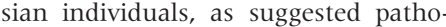
pylori infection in the first and course of $H$ pylori infection in Caucasians. Alternatively, other immunoregulatory genes in the vicinity of the IFNGRI locus such as 20 receptor $\alpha(200 \mathrm{~kb}$ dis tance) or MAP kinases 5 (600 kb distance) could harbour the causative variants. High densitiy LD mapping of the locus is required to unravel the causative genetic variants in both African and Caucasian populations. Our data support the hypothesis that the genetic diversity of the host immune system may contribute to the differences in $H$ pylori prevalence and clinical outcome in African and Caucasian populations.

S Hellmig, J Hampe, S Schreiber Department of General Internal Medicine, ChristianAlbrechts-University Kiel, Germany

Correspondence to: Professor S Schreiber, Klinik für Allgemeine Innere Medizin, Universitätsklinikum Schleswig-Holstein, Campus Kiel, Schittenhelmstraße 12, 24105 Kiel, Germany; s.schreiber@mucosa.de

\section{References}

1 Epidemiology of, and risk factors for, Helicobacter pylori infection among 3194 asymptomatic subjects in 17 populations. The EUROGAST Study Group. Gut 1993;34:1672-6.

2 Kurata JH, Haile BM. Epidemiology of peptic ulcer disease. Clin Gastroenterol 1984; 13:289-307.

3 El-Omar EM, Carrington M, Chow WH, et al. Interleukin-1 polymorphisms associated with increased risk of gastric cancer. Nature 2000:404:398-402.

4 Thye T, Burchard GD, Nilius M, et al. Genomewide linkage analysis identifies polymorphism in the human interferon-gamma receptor affecting Helicobacter pylori infection. Am J Hum Genet 2003;72:448-53.

5 Krawczak M, Konecki DS, Schmidtke J, et al. Allelic association of the cystic fibrosis locus and two DNA markers, XV2c and KM19, in 55 German families. Hum Genet 1988;80:78-80.

6 Mitchell HM, Ally R, Wadee A, et al. Major differences in the $\lg G$ subclass response to Helicobacter pylori in the first and third worlds. Scand J Gastroenterol 2002;37:517-22.

\section{Platelet activation in patients with irritable bowel syndrome may reflect a subclinical inflammatory response}

We read the recent article by Houghton et al and found the results very interesting (Gut 2003;52:663-70). Their observations included higher platelet concentrations of 5-hydroxytryptamine among patients with diarrhoea predominant irritable bowel syndrome (dIBS ) compared with controls. It is interesting that a small but significant subgroup of IBS patients report onset of their symptoms after an episode of acute gastroenteritis and a role of subclinical inflammatory aetiology has been suggested for the condition. ${ }^{1}$ The role of platelets in various inflammatory conditions has previously been demonstrated but their importance in IBS remains largely unknown. ${ }^{2-7}$ We recently looked at the possibility of platelet activation in IBS patients by determining surface expression of the activation markers at baseline and after stimulation. Stimulation involved the use of thrombin receptor activating peptide (TRAP), activation markers P-selectin (CD62) and glycoprotein 53 (CD63), and glycoprotein (GP) receptors GPIb-IX and GPIIb/GPIIIa, using whole blood flow cytometric analysis (Becton Dickenson Flow Cytometer). ${ }^{8} 9$

Twenty consecutive IBS patients (18 females), mean age 29 years (20-62), fulfilling the Rome II criteria (90\% d-IBS) and 15 healthy controls ( 11 females), mean age 28 years (22-49), were included. Raised inflammatory markers, previous bowel dis- 
ease or surgery, diverticulosis, and current or recent (past four weeks) use of non-steroidal anti-inflammatory drugs were exclusion criteria.

Standard venepuncture precautions were observed for sample collection and final analysis. ${ }^{8}$ A fluorescein isothiocynate (FITC) conjugated GPIb specific antibody was used to gate around the platelet population and list mode data on 10000 platelets acquired. Mean fluorescence intensity (MFI) was used to quantify FITC labelled GPIIb/GPIIIa and GPIb-IX specific antibody binding. Binding of P-selectin and GP53 to a phycoerythrin labelled monoclonal antibody was expressed as the percentage of platelets positive for that antibody (\% fluorescence). We tested varying strengths of TRAP, ranging from 110 to $670 \mathrm{~mm}$, in five controls and found maximal reactivity of circulating platelets at a concentration of $223 \mathrm{mM}$ (concentration used for activation studies). Differences between groups (p) were assessed using the MannWhitney $U$ test for unpaired data. All analyses were performed using the Minitab statistical software and SPSS for windows (10.0.5).

Baseline expression of P-selectin was significantly increased in the IBS group (median 5.9 (interquartile range (IQR) $4.4 \quad-8.9$ )) compared with healthy controls (median 4.1 $($ IQR 3.2-5.9)) $(\mathrm{p}=0.03)$, all values representing per cent expression. Baseline expression of GP53 was higher in the IBS group (median 3.0 (IQR 1.9-4.0)) compared with normal controls (median 2.3 (IQR 1.9-2.8)) but failed to reach clinical significance. TRAP stimulation resulted in increased expression of P-selectin and GP53 in both groups. Glycoprotein reactivity post stimulation was significantly lower in the IBS group compared with normal controls $(\mathrm{p}<0.05)$.

The numbers of GPIIb/IIIa and GPIb-IX receptor sites on the platelet surface for each group were calculated using a calibration curve where MFI and the corresponding number of antibody sites of multiple bead populations were plotted using a log log scale. The results in the two groups were comparable.

In IBS patients with normal routine inflammatory markers, we demonstrated a significant increase in surface expression of baseline P-selectin. The observed changes in baseline and reactive expression of platelet activation markers may support the theory of an ongoing subclinical inflammatory process in IBS. Reduced glycoprotein reactivity following TRAP stimulation in IBS may possibly signify a continuous low level platelet activation and degranulation with consequent platelet "exhaustion" and reduced expression of antigens. Precise interpretation of our results remains unclear due to the small number of included patients. Future studies involving a wider IBS population with possible subdivision based on the various disease characteristics, including determination of the possible disease triggering event, particularly a past history of gastroenteritis, may help to further clarify these observations.

A Qasim, H O'Brien, S Sebastian M O'Sullivan, M Buckley, C O' Moran Trinity College, Dublin, Ireland

Correspondence to: Dr A Quasim, Gastroenterology Department, AMNCH, Tallaght, Dublin 24, Ireland qasim@tcd.ie

\section{References}

1 Spiller RC. Postinfectious irritable bowel syndrome. Gastroenterology 2003:124:1662-71.

2 Schaufelberger HD, Uhr MR, McGuckin C, et al. Platelets in ulcerative colitis and Crohn's disease express functional interleukin-1 and interleukin-8 receptors. Eur J Clin Invest 1994;24:656-63.

3 Collins CE, Rampton DS. Platelet dysfunction: a new dimension in inflammatory bowel disease. Gut 1995;36:5-8

4 Lindemann S, Tolley ND, Dixon DA, et al. Activated platelets mediate inflammatory signalling by regulated interleukin 1 beta synthesis. J Cell Biol 2001; 154:485-90.

5 Uhr MR, Schaufelberger HD, Hilderbrand P, et al. [Thrombocytes express functional cytokine receptors in patients with Crohn's disease and receptors in patients with Crohn's disease and
ulcerative colitis]. Schweiz Med Wochenschr 1995; 125:970-4.

6 Collin CE, Rampton DS. Platelets in inflammatory bowel disease-pathogenic role and therapeutic implications. Aliment Pharmacol Ther implications. Alim

7 Sims P, Gingsberg M, Edward F, et al. Effect of platelet activation on the conformation of the plasma membrane glycoprotein Ilb/llla complex. $J$ Biol Chem 1991;266:7345-52.

8 Shattil SJ, Cunnungham M, Hoxie JA. Detection of activated platelets in whole blood using activation-dependent monoclonal antibodies and flow cytometry. Blood 1987;70:307-15.

9 Schmitz G, Rothe G, Ruf A, et al. European Working Group on Clinical Cell Analysis: Consensus protocol for the flow cytometric characterisation of platelet function. Thromb Haemost 1998;79:885-96.

\section{CORRECTIONS}

Two errors have been noted in the paper by CJ Hawkey et al in the June issue (Incidence of gastroduodenal ulcers in patients with rheumatoid arthritis after 12 weeks of rofecoxib, naproxen, or placebo: a multicentre, randomised, double blind study. Gut 2003:52:820-6). On page 822, the lower $95 \%$ CI for the difference between rofecoxib and placebo $(4.05)$, is given as 93.37 rather than 3.37. Also, in the key to fig 2, the dose of rofecoxib is given as $500 \mathrm{mg}$ instead of $50 \mathrm{mg}$.

In the letter by Siveke et al (Gut 2003; 52 1531) the author list was ordered incorrectly as JT Siveke, C Folwaczny and C Herberhold. The correct order for the listing of authors should have been JT Siveke, C Herberhold and C Folwaczny. This was due to a technical error for which the journal apologises.

\section{NOTICES}

\section{British Society of Gastroenterology Paul Brown Travel Fellowships}

The Paul Brown Travel Fellowships are awarded by the Endoscopy Committee of the BSG. They are intended to assist trainee gastroenterologists and established consultants in visits to units outside the United Kingdom for specialist experience and training in endoscopy.

Specialist registrars who have not achieved their CCST are expected to have the approval of their Postgraduate Dean and their Regional Training Director when they apply for a Travel Fellowship. Applicants are expected to provide confirmation that they have been accepted for training in the unit that they wish to visit.

Successful applicants will be expected to provide a brief written report to the Endoscopy Committee of the outcome of their visit.

Application forms are available from the British Society of Gastroenterology Office, 3 St Andrew's Place, London NWI 4LB. Email: bsg@mailbox.ulcc.ac.uk

\section{Hong Kong-Shanghai International Liver Congress 2004}

This conference will be held on 14-17 February 2004 in Hong Kong. The topic of the conference is "Liver Diseases in the PostGenomic Era". Further details: Ms Kristie Leung, Room 102-105 School of General Nursing, Queen Mary Hospital, 102 Pokfulam Road, Hong Kong. Tel: +852 2818 4300/8101 2442; fax: +852 2818 4030; email: kristieleung@hepa2004.org; website: www.hepa2004.org

\section{PET/CT and SPECT/CT Imaging in Medical, Radiation, Surgical and Nuclear Oncology}

This continuing medical education programme will take place on 19-20 March 2004 at Johns Hopkins University School of Medicine, Baltimore, Maryland, USA. Further details: Office of Continuing Medical Education, Johns Hopkins University School of Medicine, Turner 20, 720 Rutland Avenue, Baltimore, Maryland 21205-2195. Tel: +1 410 955 2959; fax: +1 410955 0807; email: cmenet@jhmi.edu; website:www.hopkinscme. org

\section{$39^{\text {th }}$ Annual Meeting of the European Association for the Study of the Liver} This meeting will be held on 15-19 April 2004 in Berlin, Germany. Further details: Secretariat, c/o Kenes International, 17 rue du Cendrier, PO Box 1726, CH-1211 Geneva, Switzerland. Tel: +41 22908 0488; fax: +41 22 732 2850; email: info@easl.ch; website: www.easl.ch/easl2004

- Deadline for receipt of abstracts: 16 November 2003

- Deadline for early registration 10 February 2004

\section{Second Sheffield Multi-Disciplinary Colorectal Meeting}

There will be a multi-disciplinary symposium for surgeons, physicians, radiologists and specialist nurses on 9 January 2004. The faculty includes: Wendy Atkin —St Mark's (London), Professor Jonathan Rhodes University of Liverpool, Professor John Scholefield -Nottingham, Dr S Taylor-St Mark's Hospital, Mr Andrew ShorthouseSheffield, Dr Stewart Riley-Sheffield, and Karen Smith-Nurse Endoscopist at Sheffield. The Second Sheffield MultiDisciplinary Colorectal Meeting takes place between $10 \mathrm{am}$ and $5 \mathrm{pm}$ at the Postgraduate Centre, Northern General Hospital, Sheffield. The registration fee is $£ 25$. For further details, please contact: Anne Smedley, Secretary to $\mathrm{Mr}$ AJ Shorthouse, Royal Hallamshire Hospital, Glossop Road, Sheffield, S19 2JF. 